\title{
Overlap of Five Chronic Pain Conditions: Temporomandibular Disorders, Headache, Back Pain, Irritable Bowel Syndrome, and Fibromyalgia
}

Gary D. Slade, BDSc, DDPH, PhD Division of Pediatric and Public Health Adams School of Dentistry

Department of Dental Ecology

Department of Epidemiology

Gillings School of Global Public Health

University of North Carolina

Chapel Hill, North Carolina, USA

\section{Joel D. Greenspan, PhD}

Department of Neural and Pain Sciences

Brotman Facial Pain Clinic

Center to Advance Chronic Pain Research

School of Dentistry

University of Maryland

Baltimore, Maryland, USA

Roger B. Fillingim, PhD

Department of Community Dentistry and Behavioral Science

Pain Research and Intervention Center of Excellence

College of Dentistry

University of Florida

Gainesville, Florida, USA

William Maixner, DDS, PhD

Department of Anesthesiology

Center for Translational Pain Medicine

Duke University

Durham, North Carolina, USA

Sonia Sharma, BDS, MS, PhD

Department of Oral Diagnostic Sciences

University at Buffalo School of Dental

Medicine

Buffalo, New York, USA;

Department of Orofacial Pain and Jaw

Function

Faculty of Odontology

Malmö University

Malmö, Sweden

Richard Ohrbach, DDS, PhD

Department of Oral Diagnostic Sciences

School of Dental Medicine

University at Buffalo

Buffalo, New York, USA

Correspondence to:

Dr Gary D. Slade

UNC School of Dentistry, Koury Oral

Health Sciences, Room 4501E

385 South Columbia Street, CB\#7455

Chapel Hill, NC 27599-7455, USA

Fax: 919-966-5339

Email:gary_slade@unc.edu

Submitted August 7, 2019; accepted

February 26, 2020.

(C)2020 by Quintessence Publishing Co Inc.
Aims: To assess cohort retention in the OPPERA project and to compare the degree of overlap between pairs of chronic overlapping pain conditions (COPCs) using a cross-sectional analysis of data from 655 adults who completed followup in the OPPERA study. Methods: Subjects were classified for the absence or presence of each of the five COPCs. The extent of overlap beyond chance was quantified using odds ratios, which were calculated using binary logistic regression models. Results: While overlap was the norm, its magnitude varied according to COPC: $51 \%$ of people with headache had one or more overlapping COPCs, and this proportion increased to $90 \%$ for people with fibromyalgia. The degree of overlap between pairs of COPCs also varied considerably, with odds ratios being greatest for associations between musculoskeletal conditions (fibromyalgia, temporomandibular disorders, and low back pain) and less pronounced for overlap involving headache or IBS. Furthermore, univariate associations between some pairs of COPCs were nullified after adjusting for other COPCs. Conclusion: There was greater overlap between fibromyalgia and either temporomandibular disorders or low back pain than between other pairs of COPCs. While musculoskeletal conditions exhibited some features that could be explained by a single functional syndrome, headache and irritable bowel syndrome did not. J Oral Facial Pain Headache 2020;34(suppl):s15-s28. doi: 10.11607/ofph.2581

Keywords: back pain, fibromyalgia, irritable bowel syndrome, temporomandibular disorder

$\mathrm{P}$ ain conditions feature prominently among chronic syndromes for which there is no apparent underlying cause. ${ }^{1}$ Five prototypic examples are temporomandibular disorders (TMD), headache, irritable bowel syndrome (IBS), low back pain (LBP), and fibromyalgia. While there are subtypes of each pain condition that are defined in terms of clearly identifiable causes (for example, headache attributed to infection), these occur infrequently. Instead, the most prevalent forms of these five pain conditions are grouped using labels such as "idiopathic pain disorders,"2 "chronic overlapping pain conditions,"3 "central sensitivity syndromes,"4 and, with the exception of headache, "functional pain syndromes." ${ }^{5}$ Hereafter, the collective term "chronic overlapping pain conditions" (COPCs) is used, consistent with current terminology favored by the National Institutes of Health $(\mathrm{NIH}){ }^{6}$

Overlap is a defining feature of these five COPCs. ${ }^{7}$ In principle, disease symptoms can overlap for several reasons, including the presence of common etiologic pathways. ${ }^{8}$ The most prominent such pathway thought to account for overlap is central sensitization, a process of enhanced synaptic efficacy that amplifies sensory and nociceptive stimuli. ${ }^{9}$ While aspects of central sensitization can be demonstrated using cellular and animal experimental studies, there is no clinically applicable method to measure it directly in humans. Instead, the existence of central sensitization in humans is inferred from phenotypic characteristics that are associated with central sensitization. ${ }^{10}$ This adds to the enigma of COPCs: while central sensitization is probably a major reason for their overlap, this hypothesis cannot be directly tested in the absence of a validated clinical method to demonstrate central sensitization in patients. 
The primary scientific aim of the present study was to quantify the degree of overlap among the five COPCs. Overlap was quantified using odds ratios (ORs), and it was hypothesized that, if all five COPCs could be explained by an underlying pain syndrome, the ORs of associations between all possible pairs of COPCs would be of a similar magnitude. A secondary aim was to evaluate demographic variation in the occurrence of COPCs. This paper also conducted a sensitivity analysis to evaluate assumptions about statistical weights used for data analysis and to assess the impact of alternative classifications for headache and fibromyalgia. As background to those aims, and to provide methodologic background relevant to other papers in this volume, cohort retention and factors associated with it are also described.

\section{Materials and Methods}

This manuscript is organized according to STROBE guidelines. ${ }^{11}$ The primary data collection was from National Institute of Dental and Craniofacial Research (NIDCR) Study Protocol 12-052-E, conducted in OPPERA-2, the second phase of the OPPERA project (Orofacial Pain: Prospective Evaluation and Risk Assessment). The study was reviewed and approved by the University of North Carolina Office of Human Research Ethics (study 13-2232).

\section{Study Design, Setting, and Participants}

This cross-sectional study used data from adults originally recruited into the first phase of the OPPERA project, OPPERA-1, between May 2006 and May 2013. Longitudinal changes in TMD and its risk factors within this prospective cohort study have been reported previously. ${ }^{2}$ However, four of the COPCs investigated in the current study were not assessed at baseline; hence, the current analysis is cross-sectional. Other papers have described details of recruitment and data collection, including subsequent follow-up. ${ }^{13,14}$ In summary, the target population was a convenience sample of volunteers recruited from communities in and around four US academic health centers located at: University at Buffalo, Buffalo, New York; University of Florida, Gainesville, Florida; University of Maryland, Baltimore, Maryland; and University of North Carolina, Chapel Hill, North Carolina. Adults aged 18 to 44 years were selected from two strata based on the presence or absence of TMD. A total of 3,258 subjects with examiner-verified absence of TMD were enrolled into a prospective cohort study of TMD incidence between May 2006 and November 2008; in parallel, 1,088 subjects-cases with examiner-verified painful TMD-were recruited for a case-control study of TMD between May 2006 and May 2013. (Controls for the case-control analysis were selected from enrollees in the prospective cohort study.)

The target population for this analysis was all participants who enrolled in the original OPPERA-1 study. Follow-up for the OPPERA-2 study occurred between December 2014 and May 2016, when attempts were made to contact all subjects who had not previously withdrawn from OPPERA-1. Up to six contacts were attempted using telephone, email, and address information collected in OPPERA-1. For those who consented and attended research clinics for OPPERA-2, data were collected using clinical examinations, quantitative sensory testing, cardiovascular measures of autonomic function, blood samples, and self-report questionnaires. For others who were unable or unwilling to attend study clinics, questionnaires were completed at home; however, those questionnaires were not sufficient to classify TMD or fibromyalgia, and so those subjects were not included in this analysis. Likewise, this analysis excluded OPPERA-1 enrollees who could not be contacted or who withdrew from OPPERA-1 prior to December 2014.

\section{Classification of COPCs}

TMD was classified by examiners who used the Diagnostic Criteria for TMD (DC/TMD). ${ }^{15}$ In summary, to be classified as a TMD case, subjects had to have all four of the following findings: (1) history of orofacial pain in examiner-verified locations of the masseter, temporalis, submandibular, or temporomandibular joint (TMJ) area(s) and/or history of headache in the verified location of the temporal region that had occurred on 5 or more of the 30 days preceding the examination; (2) evoked pain in the same muscles and/or TMJ(s) following palpation of those structures or jaw maneuvers; (3) reported familiarity of evoked pain, as judged by a positive response to the question "Was the pain you felt [during palpation or jaw maneuver] familiar to the pain [or temporal headache] that you reported during the last 30 days?"; and (4) pain that was modified by jaw function, as judged by a positive response to the question "During the last 30 days, was any of the pain modified by chewing hard food, opening the mouth, jaw habits such as clenching, or other jaw activities?"

Headache was classified using responses to a pain symptom questionnaire developed for this study (see Ohrbach et al, Appendix 1, current issue). It included questions about symptoms of tension-type headache (TTH) and migraine during the preceding 12 months. Subjects who experienced more than one type of headache were asked to provide responses separately for up to three different types of headache. For each type of headache reported, TTH 
classification was based on criteria described for the International Classification of Headache Disorders, third edition (ICHD-3). ${ }^{16}$ Specifically, TTH was classified when subjects met the ICHD-3 criteria for infrequent TTH, frequent TTH, or chronic TTH (probable TTH was not sufficient for TTH classification in this study). The questionnaire also asked about symptoms of migraine, with the original intention of classifying four types of migraine using the ICHD-3 criteria. However, due to a computer programming error at the data coordinating center, the data entered for one of the migraine symptoms were not captured in the study datasets. (The impact of this error is addressed below in Sensitivity Analysis.) For this analysis, migraine was instead classified using questions that approximated the ID-Migraine questionnaire, ${ }^{17}$ which were adequately captured in datasets. Specifically, migraine was classified when subjects reported headache(s) on 1 or more day per month and at least two of three symptoms accompanying the headache: nausea, sensitivity to light, or being kept from everyday activities. Study participants' binary headache classification was then based on the presence of TTH according to the ICHD-3, migraine according to the ID-Migraine, or both during the preceding 3 months.

IBS was classified using responses to four questions in the pain symptom questionnaire that were adapted from the Rome III diagnostic criteria. ${ }^{18}$ Subjects were classified with IBS if they met both of the following criteria: (1) abdominal pain on at least 1 day in the preceding 3 months that was not related to menstrual periods; and (2) pain that was associated with at least two symptoms of bowel function (ie, pain altered by bowel movements; greater frequency of bowel movements; less frequency of bowel movements; looser stools; harder stools).

LBP was classified using responses to screening questions recommended for studies of back pain prevalence ${ }^{19}$ that were also included in the pain symptom questionnaire. Subjects were classified with LBP if they reported pain that occurred in the lower back (as indicated with a shaded manikin drawing) during the preceding 3 months that was not related to fever or menstruation and that restricted usual activities for at least 1 day.

Fibromyalgia was classified based on findings from examination and a pain symptom questionnaire, consistent with the 1990 American College of Rheumatology (ACR) criteria. ${ }^{20}$ Subjects were classified with fibromyalgia when $\geq 11$ of 18 body sites were tender to algometer-delivered pressure of up to $4.0 \mathrm{~kg} / \mathrm{cm}^{2}$ and when the tenderness occurred in both the axial skeleton and in at least one set of opposing diagonal quadrants of the body. Also, fibromyalgia cases had to report a history of pain lasting for at least 1 day per month in the preceding 3 months. Concordance between this 1990 classification of fibromyalgia and the subsequent $2011^{21}$ classification method is addressed below in Sensitivity Analysis.

\section{Self-Reported Pain on the Body Manikin}

Regardless of their COPC case classification, all study participants completed a questionnaire that included a body manikin on which participants marked any of 42 named pain locations at which pain had been experienced for at least 1 day in the preceding 3 months. The goal was to enumerate the full anatomical extent of the pain, including pain that might fall short of thresholds used for COPC case classification. The drawing and details of the questionnaire are described in another OPPERA paper in this volume (see Ohrbach et al, current issue).

\section{Statistical Analyses}

The initial methodologic analysis evaluated factors associated with cohort retention in the OPPERA study. This was important because the sample for this cross-sectional analysis represented only a small proportion of the subjects who enrolled up to 10 years earlier in the original OPPERA-1 study. At that time, study participants reflected demographic variation in the US, as benchmarked against population census data for the four study sites. ${ }^{14}$ Factors found to be associated with cohort retention were used in a multivariable binary logistic regression model that predicted probability of cohort retention for individual OPPERA-1 enrollees (ie, 3,258 subjects who were enrolled as controls, and 1,088 subjects who were enrolled as chronic TMD cases). As explained in detail in the appendices, analytic weights were then computed for the 655 subjects retained in the cohort. Weights were the product of the inverse of the model-predicted probability of cohort retention multiplied by the inverse of the sampling probability for TMD cases and controls in OPPERA-1. Sampling probability was assumed to be $7.5 \%$ for TMD cases (ie, a midpoint between the nationally reported prevalence based on TMD symptoms ${ }^{22}$ and the examiner-verified prevalence in a sample of women in the New York metropolitan area ${ }^{23}$ ). Such weighting is necessary to make valid estimates of an association between any two variables (eg, headache and LBP) in a sample that was originally stratified according to a third variable (in this instance, presence or absence of chronic TMD in OPPERA-1). ${ }^{24}$ Unless stated otherwise, all means, percentages, and measures of association for the scientific aims in this paper were calculated using generalized estimating equation (GEE) regression models. This was achieved with the GENMOD procedure in SAS version 9.4 using the computed analytic weights and appropriate variance correction. ${ }^{25}$ 
The models also apply a variance correction because subjects in the analytic sample are a "stand-in" 25 for the original sample.

For descriptive purposes, study participants were cross-classified according to the presence or absence of the five COPCs, and the weighted frequencies were used to create pie charts describing permutations of overlap among subjects with one or more COPCs. The primary measure of overlap was the odds ratio (OR) of associations between pairs of COPCs. Weighted ORs were calculated using GEE models for logistic binary regression, first as a univariate association (ie, a single COPC predicted by one other (COPC) and second as a multivariable association (ie, a single COPC predicted by all four other COPCs in a multivariable model). The latter is justified by recognizing that the four predictor COPCs in several of the models are, themselves, at least moderately correlated, which increases variance estimates in the model. Instead, the focus is on point estimates from the adjusted model which, in the multivariable model, signify the extent of overlap between pairs of COPCs, which might be due to an underlying functional pain syndrome and not merely co-occurrence of the two COPCs.

For the second aim, demographic characteristics of cases and noncases were compared for each COPC. GEE models for logistic regression were used to test for differences between cases and controls. Likewise, the number of COPCs (ranging from 0 to 5) was computed, and weighted analysis was used to estimate percentages of subjects in each category. GEE models for linear regression were used to test for differences in the mean number of COPCs per subject.

\section{Sensitivity Analysis}

For the main analysis described above, fibromyalgia was classified using the 1990 criteria of the $\mathrm{ACR}^{20}$ because that classification had also been used in OPPERA-1. However, when plans were being developed for OPPERA-2, a revised classification for fibromyalgia was published. ${ }^{21} \mathrm{~A}$ significant part of the revision discarded examiners' pressure pain assessments and instead used subjects' reported location(s) of pain using a body manikin. The methods for OPPERA-2 were therefore modified to collect data for fibromyalgia classification using both systems. To determine the impact of the different classification systems, two types of sensitivity analysis were conducted: (1) Case classifications were cross-classified to calculate sensitivity and specificity of the 1990 criteria, with the 2011 criteria used as the reference standard; and (2) ORs of association between pairs of COPCs were repeated, this time using the 2011 criteria instead of the 1990 criteria.
As noted previously, responses in the pain symptoms questionnaire concerning headache were not all captured correctly in the study database, with the consequence that migraine could not be classified according to ICHD-3 criteria as intended. Specifically, the database did not capture the response "pain is throbbing or pulsating." This omission was significant because throbbing or pulsating quality of headache is one of the four headache characteristics required for the ICHD-3 classification of migraine. ${ }^{16}$ Specifically, criterion $\mathrm{C}$ requires occurrence of two or more of the following characteristics: unilateral location; pulsating quality; moderate or severe pain intensity; and aggravation by or causing avoidance of routine physical activity. Because of the error, migraine was instead classified using the ID-Migraine questionnaire ${ }^{26}$ which does not use symptoms of throbbing or pulsating for its case classification. However, after discovering the error, paper questionnaires were used while the database was changed, yielding 422 pain symptom questionnaires that were completed correctly: 95 of them were for subjects included in this analysis, and the remaining 327 were for people who participated in other protocols within the OPPERA-2 study. To gauge the extent of concordance between the ID-Migraine and ICHD-3 classifications, responses from those subjects were cross-classified to calculate sensitivity and specificity.

Finally, to illustrate the effects of weighting in data analysis, unweighted ORs of associations between pairs of COPCs were generated using conventional binary logistic regression models, as would be done for analysis of data from a convenience sample. The models were analogous to the GEE models described above, except that they did not use analytic weights or variance adjustments. Hence, the estimates represent a "worst-case assumption" for calculating associations, equivalent to what would be obtained assuming a convenience sample.

To explore the effects of a more plausible range of assumptions, associations between pairs of COPCs were generated using 36 simulations that allowed for variation in: (1) the predicted probability of retention in the OPPERA cohort and (2) variation in assumed prevalence of chronic TMD in the population from which the OPPERA-1 subjects were originally selected. The six simulations of predicted probability were generated using random, split-half cross-validation for the logistic regression model described above (ie, where cohort retention was predicted using OPPERA-1 TMD case classification, study site, age, gender, race, English language, and household income). The six simulations of presumed TMD prevalence varied from 0.025 to 0.150 . For each of the simulated prevalence assumptions, six univariate and 
Table 1 Baseline Sociodemographic Characteristics Associated with Loss to Follow-up in OPPERA

\begin{tabular}{|c|c|c|c|c|c|c|}
\hline & \multicolumn{2}{|c|}{ Baseline OPPERA-1 cohort } & \multicolumn{2}{|c|}{ OPPERA-2 examination } & \multirow[b]{2}{*}{$\%$ of baseline } & \multirow[b]{2}{*}{$P$} \\
\hline & Subjects, $\mathrm{n}$ & $\%$ & Subjects, $\mathrm{n}$ & $\%$ & & \\
\hline All subjects & 4,346 & 100.0 & 655 & 100.0 & 15.1 & \\
\hline \multicolumn{7}{|c|}{ TMD case classification in OPPERA-1 } \\
\hline Chronic TMD & 1,088 & 25.0 & 172 & 26.3 & 15.8 & .1233 \\
\hline Incident TMD & 260 & 6.0 & 49 & 7.5 & 18.8 & \\
\hline TMD free & 2,998 & 69.0 & 434 & 66.3 & 14.5 & \\
\hline \multicolumn{7}{|l|}{ OPPERA-1 study site } \\
\hline Florida & 1,149 & 26.4 & 120 & 18.3 & 10.4 & $<.0001$ \\
\hline Maryland & 996 & 22.9 & 58 & 8.9 & 5.8 & \\
\hline North Carolina & 1,157 & 26.6 & 264 & 40.3 & 22.8 & \\
\hline New York & 1,044 & 24.0 & 213 & 32.5 & 20.4 & \\
\hline \multicolumn{7}{|c|}{ Age at enrollment in OPPERA-1, y } \\
\hline $18-24$ & 2,091 & 48.1 & 225 & 34.4 & 10.8 & $<.0001$ \\
\hline $25-34$ & 1,255 & 28.9 & 200 & 30.5 & 15.9 & \\
\hline $35-44$ & 1,000 & 23.0 & 230 & 35.1 & 23.0 & \\
\hline \multicolumn{7}{|l|}{ Gender } \\
\hline Female & 2,697 & 62.1 & 452 & 69.0 & 16.8 & $<.0001$ \\
\hline Male & 1,649 & 37.9 & 203 & 31.0 & 12.3 & \\
\hline \multicolumn{7}{|l|}{ Race/ethnicity } \\
\hline Asian & 344 & 7.9 & 24 & 3.7 & 7.0 & $<.0001$ \\
\hline Black or African-American & 1,187 & 27.3 & 170 & 26.0 & 14.3 & \\
\hline Hispanic & 277 & 6.4 & 27 & 4.1 & 9.7 & \\
\hline Other & 136 & 3.1 & 16 & 2.4 & 11.8 & \\
\hline White & 2,402 & 55.3 & 418 & 63.8 & 17.4 & \\
\hline \multicolumn{7}{|l|}{ Marital status } \\
\hline Never married & 3,005 & 69.1 & 378 & 57.7 & 12.6 & $<.0001$ \\
\hline Married, cohabiting, divorced & 1,258 & 28.9 & 267 & 40.8 & 21.2 & \\
\hline Not stated & 83 & 1.9 & 10 & 1.5 & 12.0 & \\
\hline
\end{tabular}

six multivariable ORs of association between each pair of COPCs were generated (the multivariable models adjusted for the three other COPCs, as described for the main analysis). The mean and range of ORs were generated to represent descriptive data about the impact of assumptions made when calculating weights.

\section{Results}

\section{Study Sample}

Of the 1,088 people originally enrolled into OPPERA-1 as TMD cases, $172(15.8 \%)$ are included in this analysis. The remainder were lost to follow-up: 17 (1.6\%) were examined but lacked sufficient data for classification of all five COPCs; 84
(7.7\%) completed questionnaires but no examination; 582 (53.5\%) could not be contacted; and 233 (21.4\%) withdrew from OPPERA-1 before 2014. Among the 3,258 originally enrolled TMD-free controls, $493(14.8 \%)$ are included in this analysis. Loss to follow-up in that group was due to: $21(0.6 \%)$ insufficient examination data; 281 (8.6\%) questionnaires only; $1,794(55.1 \%)$ noncontactable; and 679 (20.8\%) withdrawn from OPPERA-1.

While the rate of cohort retention did not vary significantly between enrolled strata (ie, TMD cases and controls in OPPERA-1), there were significant differences according to baseline sociodemographic characteristics (Table 1). In the unweighted analysis, greater cohort retention was associated with older age, female sex, white race, being married, having English as the first language, having health insurance, 
Table 1 (cont'd) Baseline Sociodemographic Characteristics Associated with Loss to Follow-up in OPPERA

\begin{tabular}{|c|c|c|c|c|c|c|}
\hline & \multicolumn{2}{|c|}{ Baseline OPPERA-1 cohort } & \multicolumn{2}{|c|}{ OPPERA-2 examination } & \multirow[b]{2}{*}{$\%$ of baseline } & \multirow[b]{2}{*}{$P$} \\
\hline & Subjects, $\mathrm{n}$ & $\%$ & Subjects, $n$ & $\%$ & & \\
\hline \multicolumn{7}{|l|}{ First language spoken } \\
\hline English & 3,806 & 87.6 & 612 & 93.4 & 16.1 & $<.0001$ \\
\hline Other language & 497 & 11.4 & 38 & 5.8 & 7.6 & \\
\hline Not stated & 43 & 1.0 & 5 & 0.8 & 11.6 & \\
\hline \multicolumn{7}{|c|}{ Rating of satisfaction with material standards in life } \\
\hline Low $(0-5)$ & 1,323 & 30.4 & 169 & 25.8 & 12.8 & .0004 \\
\hline Mid (6-8) & 1,903 & 43.8 & 326 & 49.8 & 17.1 & \\
\hline High (9-10) & 1,031 & 23.7 & 155 & 23.7 & 15.0 & \\
\hline Not stated & 89 & 2.0 & 5 & 0.8 & 5.6 & \\
\hline \multicolumn{7}{|c|}{ Rating of satisfaction with financial situation } \\
\hline Low (0-3) & 1,483 & 34.1 & 188 & 28.7 & 12.7 & .0007 \\
\hline Mid (4-6) & 1,583 & 36.4 & 262 & 40.0 & 16.6 & \\
\hline High (7-10) & 1,216 & 28.0 & 202 & 30.8 & 16.6 & \\
\hline Not stated & 64 & 1.5 & 3 & 0.5 & 4.7 & \\
\hline \multicolumn{7}{|l|}{ Health insurance coverage } \\
\hline Yes & 3,407 & 78.4 & 554 & 84.6 & 16.3 & .0002 \\
\hline No & 769 & 17.7 & 82 & 12.5 & 10.7 & \\
\hline Not stated & 170 & 3.9 & 19 & 2.9 & 11.2 & \\
\hline \multicolumn{7}{|l|}{ Highest level of schooling } \\
\hline High school or less & 708 & 16.3 & 83 & 12.7 & 11.7 & $<.0001$ \\
\hline $\begin{array}{l}\text { Post-high school or some } \\
\text { college }\end{array}$ & 1,756 & 40.4 & 229 & 35.0 & 13.0 & \\
\hline Completed college & 1,155 & 26.6 & 207 & 31.6 & 17.9 & \\
\hline Postgraduate & 652 & 15.0 & 131 & 20.0 & 20.1 & \\
\hline Not stated & 75 & 1.7 & 5 & 0.8 & 6.7 & \\
\hline \multicolumn{7}{|l|}{ Annual household income } \\
\hline$<\$ 20,000$ & 735 & 16.9 & 85 & 13.0 & 11.6 & $<.0001$ \\
\hline$\$ 20,000-<\$ 40,000$ & 771 & 17.7 & 136 & 20.8 & 17.6 & \\
\hline$\$ 40,000-<\$ 80,000$ & 920 & 21.2 & 210 & 32.1 & 22.8 & \\
\hline$\geq \$ 80,000$ & 929 & 21.4 & 129 & 19.7 & 13.9 & \\
\hline Not stated & 991 & 22.8 & 95 & 14.5 & 9.6 & \\
\hline
\end{tabular}

and greater educational attainment. Cohort retention varied according to household income and satisfaction with material or financial circumstances, although not in a linear manner. The largest differences in cohort retention were observed between study sites, ranging from 5.8\% at the University of Maryland to $22.8 \%$ at the University of North Carolina.

Appendix 1 (see all appendices in the online version of this article at www.quintpub.com/journals) summarizes associations between cohort retention and the larger set of 134 baseline measures of baseline phenotypes. When ranked according to $P$ value for the univariate odds ratio, 9 of the 14 significant variables were cardiovascular measures of autonomic function. However, after adjustment for study site and demographics, only two baseline measures were significantly associated with cohort retention: posttraumatic stress syndrome and smoking both predicted lower probability of cohort retention.

\section{Demographic Characteristics Associated with COPCs}

The OPPERA-2 sample of 655 study participants ranged in age from 22 to 53 years (median $=36$ years). 
Table 2 Demographic Characteristics in Cases and Noncases of the Five COPCs

\begin{tabular}{|c|c|c|c|c|c|c|c|c|c|c|}
\hline & \multicolumn{2}{|c|}{ TMD } & \multicolumn{2}{|c|}{ Headache } & \multicolumn{2}{|c|}{ IBS } & \multicolumn{2}{|c|}{ LBP } & \multicolumn{2}{|c|}{ Fibromyalgia } \\
\hline & Noncase & Case & Noncase & Case & Noncase & Case & Noncase & Case & Noncase & Case \\
\hline Unweighted $n$ & 473 & 182 & 385 & 270 & 497 & 158 & 516 & 139 & 603 & 52 \\
\hline Weighted $n$ & 547 & 108 & 454 & 201 & 521 & 134 & 556 & 99 & 631 & 24 \\
\hline \multicolumn{11}{|c|}{ Age group, $y$ : Weighted $\%$ of subjects } \\
\hline $22-29$ & 28.5 & 40.4 & 28.9 & 33.9 & 26.6 & 45.4 & 32.1 & 21.1 & 30.2 & 36.7 \\
\hline 30-39 & 41.5 & 34.7 & 41.6 & 37.5 & 44.5 & 24.3 & 41.5 & 34.1 & 40.4 & 38.8 \\
\hline $40-49$ & 22.1 & 23.2 & 22.1 & 22.6 & 22.4 & 21.6 & 19.7 & 36.5 & 22.2 & 23.9 \\
\hline $50-53$ & 8.0 & 1.7 & 7.5 & 5.9 & 6.5 & 8.7 & 6.7 & 8.3 & 7.2 & 0.6 \\
\hline$P$ & \multicolumn{2}{|c|}{.004} & \multicolumn{2}{|c|}{.734} & \multicolumn{2}{|c|}{.015} & \multicolumn{2}{|c|}{.079} & \multicolumn{2}{|c|}{.017} \\
\hline
\end{tabular}

Gender: Weighted \% of subjects

\begin{tabular}{|c|c|c|c|c|c|c|c|c|c|c|}
\hline Male & 43.0 & 38.8 & 48.3 & 28.9 & 41.3 & 46.3 & 42.1 & 43.3 & 43.1 & 22.8 \\
\hline Female & 57.0 & 61.2 & 51.7 & 71.1 & 58.7 & 53.7 & 57.9 & 56.7 & 56.9 & 77.2 \\
\hline$P$ & \multicolumn{2}{|c|}{.574} & \multicolumn{2}{|c|}{.001} & \multicolumn{2}{|c|}{.470} & \multicolumn{2}{|c|}{.872} & & \\
\hline
\end{tabular}

Race/ethnicity: Weighted \% of subjects

\begin{tabular}{|c|c|c|c|c|c|c|c|c|c|c|}
\hline White & 52.2 & 50.7 & 50.4 & 55.5 & 49.8 & 60.1 & 50.0 & 62.9 & 51.9 & 52.7 \\
\hline $\begin{array}{l}\text { Black or African } \\
\text { American }\end{array}$ & 31.0 & 23.7 & 29.9 & 29.6 & 30.9 & 25.3 & 31.0 & 22.9 & 30.1 & 21.0 \\
\hline Other & 16.8 & 25.6 & 19.8 & 15.0 & 19.2 & 14.6 & 19.0 & 14.2 & 18.0 & 26.2 \\
\hline$P$ & \multicolumn{2}{|c|}{.426} & \multicolumn{2}{|c|}{.579} & \multicolumn{2}{|c|}{.335} & \multicolumn{2}{|c|}{.203} & & \\
\hline
\end{tabular}

Study site: Weighted \% of subjects

\begin{tabular}{lllllllllll} 
North Carolina & 25.6 & 29.1 & 24.1 & 31.0 & 23.9 & 35.2 & 27.3 & 20.2 & 26.5 & 17.9 \\
New York & 22.4 & 17.3 & 21.9 & 20.8 & 21.2 & 23.0 & 19.2 & 34.9 & 21.3 & 28.3 \\
Florida & 20.8 & 30.6 & 19.9 & 28.0 & 23.7 & 17.3 & 23.9 & 13.8 & 21.5 & 44.6 \\
Maryland & 31.2 & 23.0 & 34.1 & 20.3 & 31.2 & 24.6 & 29.6 & 31.2 & 30.7 & 9.3 \\
$P$ & \multicolumn{2}{c}{.203. } & \multicolumn{2}{c}{.084} & & .136 & & .006 & .097
\end{tabular}

The majority were women (69\%), 64\% were white, 30\% African-American, 4\% Asian, 4\% Hispanic, and $2 \%$ other races. In the weighted analysis that adjusted for sampling probability in OPPERA-1 and cohort retention through OPPERA-2, 58\% were women while 52\% were white, 30\% African-American, 9\% Asian, 6\% Hispanic, and 3\% other race/ethnicity. In the weighted analysis, headache was the most frequent COPC (31\% of subjects), followed by IBS (21\%), TMD (17\%), LBP (15\%), and fibromyalgia (4\%). The headache group was comprised of $10 \%$ with TTH alone, 18\% with migraine alone, and 3\% with TTH and migraine. Approximately half of the subjects $(53 \%)$ had one or more COPCs, comprised of one-third (32\%) who had one, 13\% with two, 5\% with three, $2 \%$ with four, and $1 \%$ with all five COPCs.

Table 2 reports demographic associations with each COPC. Presence of TMD, IBS, and fibromyalgia was significantly associated with younger age, whereas LBP tended to be associated with older age; in contrast, headache was not associated with age to any meaningful degree. Compared to their respective control groups, subjects with headache were more likely to be women, although gender was not significantly associated with TMD, IBS, LBP, or fibromyalgia. Meanwhile, race/ethnicity was not associated with any of the COPCs. Study site variation in COPCs was generally weak and inconsistent. When study participants were classified according to number of COPCs, there were no consistent or statistically significant patterns of association with demographic characteristics (Table 3).

\section{Frequency of Overlap Among COPCs}

Approximately one-half of study participants had at least one of the five COPCs studied, with $32 \%$ experiencing a single COPC, $12.7 \%$ experiencing two, and $8.3 \%$ experiencing three or more COPCs (Table 3). When each COPC was considered individually as an index condition, the extent of overlap with the other four COPCs was most pronounced for fibromyalgia and least pronounced for headache (Fig 1). 
Table 3 Demographic Characteristics According to Number of COPCs

\begin{tabular}{|c|c|c|c|c|c|c|c|c|c|}
\hline & \multicolumn{6}{|c|}{ No. of COPCs } & \multirow{2}{*}{$\begin{array}{c}\text { Mean } \\
\text { no. of } \\
\text { COPCs }\end{array}$} & \multicolumn{2}{|c|}{$\begin{array}{l}\text { Grouped no. of } \\
\text { COPCs }\end{array}$} \\
\hline & 0 & 1 & 2 & 3 & 4 & 5 & & $0-2$ & $3-5$ \\
\hline Unweighted $\mathrm{n}$ & 252 & 178 & 109 & 71 & 33 & 12 & & 539 & 116 \\
\hline Weighted $n$ & 307 & 209 & 83 & 33 & 15 & 6 & & 599 & 54 \\
\hline Weighted \% & 47.0 & 32.0 & 12.7 & 5.1 & 2.3 & 0.9 & & 91.7 & 8.3 \\
\hline \multicolumn{10}{|c|}{ Age group, y: Weighted $\%$ of subjects } \\
\hline $22-29$ & 24.3 & 33.4 & 48.1 & 26.5 & 10.5 & 66.9 & 1.0 & 30.8 & 26.4 \\
\hline $30-39$ & 45.8 & 39.7 & 27.1 & 34.9 & 28.3 & 28.4 & 0.7 & 41.1 & 32.3 \\
\hline $40-49$ & 21.8 & 21.8 & 14.6 & 33.8 & 60.3 & 2.3 & 1.0 & 20.8 & 37.9 \\
\hline $50-53$ & 8.0 & 5.0 & 10.3 & 4.8 & 0.9 & 2.4 & 0.7 & 7.3 & 3.5 \\
\hline$P$ & & & & & & & .084 & \multicolumn{2}{|c|}{.167} \\
\hline \multicolumn{10}{|c|}{ Gender: Weighted $\%$ of subjects } \\
\hline Male & 46.1 & 40.0 & 42.5 & 36.4 & 7.8 & 51.2 & 0.8 & 43.5 & 29.9 \\
\hline Female & 54.0 & 60.0 & 57.5 & 63.6 & 92.2 & 48.8 & 0.9 & 56.6 & 70.1 \\
\hline$P$ & & & & & & & .110 & \multicolumn{2}{|c|}{.091} \\
\hline \multicolumn{10}{|c|}{ Race/ethnicity: Weighted $\%$ of subjects } \\
\hline White & 46.5 & 55.5 & 58.7 & 68.4 & 39.7 & 52.8 & 1.0 & 51.3 & 58.6 \\
\hline $\begin{array}{l}\text { Black or African } \\
\text { American }\end{array}$ & 32.8 & 31.1 & 18.1 & 16.5 & 48.3 & 17.7 & 0.8 & 30.2 & 25.6 \\
\hline Other & 20.8 & 13.4 & 23.2 & 15.1 & 12.0 & 29.5 & 0.8 & 18.5 & 15.8 \\
\hline$P$ & & & & & & & .257 & \multicolumn{2}{|c|}{.663} \\
\hline \multicolumn{10}{|c|}{ Study site: Weighted \% of subjects } \\
\hline North Carolina & 24.3 & 24.4 & 33.4 & 44.8 & 12.2 & 22.4 & 1.0 & 25.6 & 33.2 \\
\hline New York & 20.6 & 21.7 & 21.8 & 20.4 & 37.1 & 25.9 & 0.9 & 21.2 & 25.7 \\
\hline Florida & 21.1 & 21.8 & 30.7 & 15.9 & 14.9 & 51.7 & 0.9 & 22.7 & 19.5 \\
\hline Maryland & 34.1 & 32.1 & 14.1 & 18.9 & 35.8 & 0.0 & 0.7 & 30.6 & 21.6 \\
\hline$P$ & & & & & & & .293 & \multicolumn{2}{|c|}{.481} \\
\hline
\end{tabular}

Specifically, $90 \%$ of fibromyalgia cases had one or more comorbid COPCs, with $24 \%$ having all other COPCs (ie, a total of five COPCs). In contrast, only $51 \%$ of headache cases had overlap with any other COPC, and in most instances (27\% of all headache cases), it was only one other COPC. For TMD, a large majority (78\%) of cases had one or more comorbid COPCs, although for most, the extent of overlap was limited to one or two other COPCs, and the permutations of overlapping COPCs tended be dominated by headache. Two-thirds of LBP cases had one or more comorbid COPCs, although there was no single comorbid COPC that dominated among the permutations of overlapping pains. IBS was similar, with $63 \%$ of cases featuring one or more other COPCs, again with no dominant pattern of overlap.

The specific permutations of overlap also varied according to the COPC used to define the index condition (Fig 1). For example, the comorbid COPCs that overlapped with fibromyalgia were dominated by
TMD. Interestingly, however, some other permutations were not observed. For example, there were no instances of either IBS or headache being the sole comorbid COPC in people with fibromyalgia. This is despite the fact that headache and IBS were the two most commonly occurring COPCs in the cohort overall.

\section{Self-Reported Pain on the Body Manikin}

After excluding body manikin locations that were pain landmarks for the index COPC, comorbid pain of at least 1 day's duration was reported by a large majority of the study participants who fulfilled criteria as COPC cases. In fact, for most COPCs, a majority of cases reported at least three non-COPC locations on the body manikin (Appendix 2). Specifically, 63\% of TMD cases endorsed pain at $\geq 3$ non-TMD locations, 58\% of LBP cases endorsed pain at $\geq 3$ nonback locations, $53 \%$ of IBS cases reported pain at $\geq 3$ nonabdominal locations, and $48 \%$ of headache 

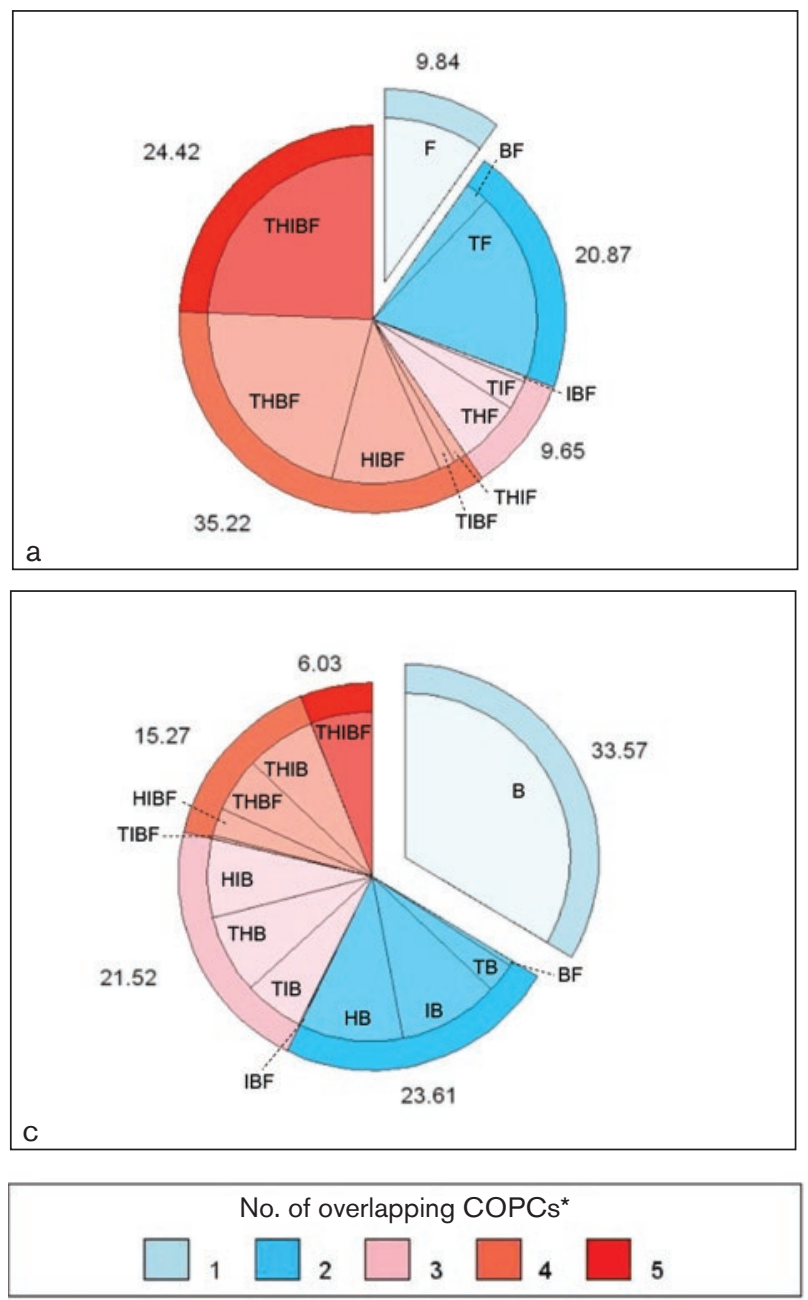

Fig 1 Overlap of five chronic pain conditions: (a) fibromyalgia, (b) TMD, (c) LBP, (d) IBS, and (e) headache cases. The percent values represent the weighted percentage of subjects with permutations of the five COPCs: $T=T M D$ (unweighted $n=182$ ); $\mathrm{H}=$ headache (unweighted $\mathrm{n}=270$ cases), $\mathrm{I}=$ irritable bowel syndrome (unweighted $n=158$ ), $B=$ low back pain (unweighted $n=139$ cases); $F=$ fibromyalgia $(n=52$ cases). Weights adjust for the sampling probabilities of TMD cases and controls when enrolled in the OPPERA-1 project and the probability of cohort retention in the OPPERA-2 analysis.

cases reported pain at $\geq 3$ nonheadache locations. This represents a much greater extent of comorbid pain than is apparent using formal COPC case classifications to signify comordity, as indicated in Fig 1, where overlap of $\geq 3$ COPCs was observed for only $17 \%$ of TMD cases, $21 \%$ of LBP cases, $12 \%$ of IBS cases, and $10 \%$ of headache cases.

\section{Measures of Association Between COPCs}

Within the complete study sample, univariate associations between each pair of COPCs were most pronounced for fibromyalgia and TMD (OR = 19.7),
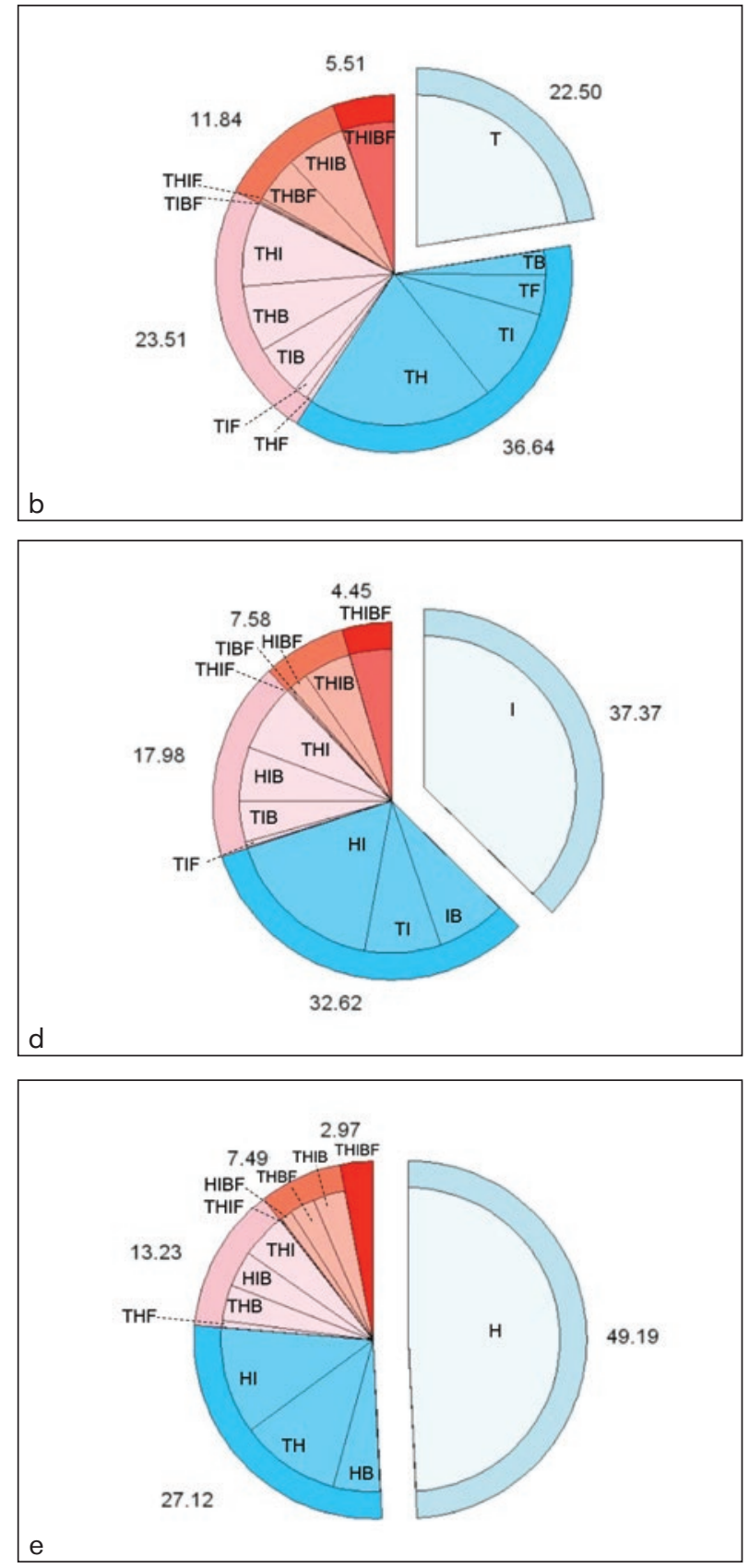

followed by fibromyalgia and LBP (OR = 10.2; unadjusted values in Table 4). Other univariate associations were less pronounced, although they likewise revealed statistically significant ORs, as signified by 95\% confidence limits $(\mathrm{CL})$ that did not overlap with the null value of 1 .

All ORs were attenuated in the multivariable analysis that adjusted for all other COPCs (adjusted values in Table 4), and in several instances, the association was nullified after adjustment. For example, in the univariate analysis, the odds of IBS were elevated 3 -fold in fibromyalgia cases relative to fibromyalgia 
Table 4 Associations Between Pairs of COPCs

\begin{tabular}{lccccc} 
& TMD & Headache & IBS & LBP & Fibromyalgia \\
\hline TMD & & $2.6(1.4,4.8)$ & $2.2(1.1,4.4)$ & $1.9(1.0,3.8)$ & $12.8(2.9,57.1)$ \\
Headache & $3.4(1.9,6.0)$ & & $1.4(0.8,2.5)$ & $1.6(0.9,2.8)$ & $1.9(0.7,5.2)$ \\
IBS & $2.9(1.6,5.3)$ & $1.9(1.1,3.2)$ & & $2.6(1.4,4.8)$ & $1.0(0.4,2.8)$ \\
LBP & $3.6(1.9,6.6)$ & $2.3(1.3,4.0)$ & $3.2(1.7,6.0)$ & & $5.5(2.2,13.4)$ \\
Fibromyalgia & $19.7(6.3,61.5)$ & $4.3(1.6,11.5)$ & $2.9(1.1,7.4)$ & $10.2(3.9,26.7)$ & \\
\hline
\end{tabular}

Data are reported as odds ratios (95\% confidence limits). Unadjusted values are below the diagonal line, and values adjusted for other COPCs are above the diagonal line.

controls $(\mathrm{OR}=2.9,95 \% \mathrm{CL}=1.1,7.4)$, whereas they were nullified in the multivariable model $(\mathrm{OR}=1.0$, $95 \% \mathrm{CL}=0.4,2.8)$. One interpretation is that the univariate contribution of fibromyalgia to IBS is sufficiently explained by the confounding effects of TMD, LBP, and headache, all of which are associated with IBS and fibromyalgia. In other words, fibromyalgia made no independent contribution to IBS after accounting for the other three COPCs. Turning to other pairs of COPCs with associations nullified in the multivariable analysis, it was notable that three were pairs involving headache; ie, headache with IBS, headache with LBP, and headache with fibromyalgia. Nonetheless, half of the associations between pairs of COPCs remained statistically significant in the multivariable models that adjusted for the other three COPCs. The strongest adjusted associations were between fibromyalgia and TMD (adjusted OR = 12.8), followed by fibromyalgia and LBP (adjusted OR = 5.5).

\section{Sensitivity Analysis}

Using the 2011 criteria for fibromyalgia, ${ }^{21} 3.3 \%$ of subjects were classified as cases compared to $3.7 \%$ based on the 1990 criteria. ${ }^{20}$ With the 2011 classification used as the reference standard, sensitivity using the 1990 classification was $52 \%$, and specificity was $98 \%$. Appendix 3 shows associations between pairs of COPCs using the 2011 classification. When compared with the corresponding analysis using the 1990 classification (Table 4), most ORs were similar in magnitude, again showing strong associations for fibromyalgia vs TMD and for fibromyalgia vs LBP. The main difference between the two classification systems concerned the association with LBP: using the examiner-based 1990 classification, the univariate OR was 10.2 (Table 4), whereas using the subject-based 2011 classification, the univariate OR was 20.1, equivalent in magnitude to the OR for fibromyalgia vs TMD (Appendix 3).

In the sensitivity analysis of headache classification, responses to the pain symptom questionnaire were available from the 422 subjects whose data were correctly captured. Using the ICHD-3 crite- ria for both types of headache, 212 were classified with TTH and/or migraine, 186 of whom were also classified as cases based on the OPPERA-2 hybrid classification of headache (ie, sensitivity $=88 \%$ ). Conversely, there were 210 subjects who had neither ICHD-3 TTH nor migraine, 194 of whom were likewise negative using the OPPERA-2 hybrid classification (ie, specificity $=92 \%$ ). When the 327 subjects from other OPPERA-2 protocols were excluded, restricting the analysis to the 95 subjects reported elsewhere in this paper, the sensitivity was $92 \%$ and the specificity $89 \%$. Appendix 4 cross-classifies the 422 subjects according to all four combinations of TTH, migraine, both, or neither and shows an additional 19 cases of discordance in the four-level classification that did not alter the two-level classification; ie, 10 instances of ICHD-3 TTH and migraine that were negative for ID-Migraine. There were also 9 instances of ICHD-3 TTH without ICHD-3 migraine that were positive for ID-Migraine migraine.

Compared to the weighted estimates reported in Table 4, the unweighted analysis of associations between pairs of COPCs produced mostly larger ORs with narrower 95\% CLs (Appendix 5). The most pronounced effect of this "worst-case assumption" for analysis was seen for the association of headache and TMD, where the unweighted, univariate OR of 6.2 (Appendix 5) was approximately twice the OR of 3.4 from the weighted analysis reported in Table 4. Appendix 6 illustrates how associations between pairs of COPCs are altered by assumptions used when computing the weights. The biggest effects were seen for associations of TMD and headache, with the unadjusted OR increasing by approximately $50 \%$ as the assumed prevalence of TMD in the original OPPERA sample increased from 0.025 (mean $\mathrm{OR}=2.6$, cross-validated range $=2.4$ to 2.8 ) to 0.150 (mean OR $=4.2$, range $=3.9$ to 4.6 ). ORs for other pairs of COPCs likewise tended to increase with assumed prevalence by small relative amounts. There was relatively small variation in the range of cross-validated ORs, which depicts variation according to assumed probability of cohort retention. 


\section{Discussion}

In this community-based sample of US adults, approximately half $(53 \%)$ had one or more of the five COPCs studied, with headache being the most frequent (31\%) and fibromyalgia the least frequent (4\%). However, the extent of overlapping COPCs was minimal for headache (ie, ORs for association with other COPCs were weakest), while it was greatest for people with fibromyalgia (ie, ORs ranged from 2.9 to 19.7). This study also took the novel step of quantifying the degree of overlap between pairs of COPCs, which was found to be most pronounced for the musculoskeletal conditions (fibromyalgia vs TMD and fibromyalgia vs LBP) and less pronounced for overlap involving headache or IBS. While there was relatively little variation in occurrence of COPCs according to gender or race/ethnicity, occurrence of TMD, IBS, and fibromyalgia was inversely associated with age. Methodologic findings from this analysis provide context that is useful when interpreting results from this paper and others in OPPERA-2.

\section{Study Limitations}

These results are from a sample of study participants first recruited up to 12 years earlier to fulfill sampling requirements for two OPPERA-1 study protocols. At that time, the vast majority came from the community at large, with only 7\% of TMD cases and $9 \%$ of TMD-free controls recruited at health center clinics. ${ }^{14}$ While this achieved the goal of representing demographic variation in the US, it must be emphasized that participants were not a random sample from the population at large. OPPERA's original sampling design also meant that it was necessary to weight the data in this analysis. This is a common situation when case-control studies assess outcomes of interest in addition to the case classification used to define cases and controls. ${ }^{24}$

Loss to follow-up is likewise common, although in this study, the strongest predictors of loss to followup were sociodemographic factors, not pain-related phenotypes, which provides some reassurance about the validity of results from other papers in this volume that investigate those phenotypes. This also meant that the probability of cohort retention, used when calculating analytic weights, could be adequately predicted using sociodemographic characteristics. As noted in the sensitivity analysis, the weighted analysis had the effect of producing more conservative measures of association (ie, less likely to reject the null hypothesis) than were obtained with the "worst-case assumption" of a simple random sample. Using a more plausible range of assumptions for analytic weights, it was found that the presumed prevalence of TMD underlying OPPERA's original case-control sampling design had the greatest impact in creating conservative estimates. In contrast, the cross-validated estimates showed that assumptions concerning cohort retention had much smaller effects on ORs of association between pairs of COPCs. While this was surprising given the low rate of cohort retention, it also provides further reassurance regarding adjustment for the primary inclusion criterion (presence or absence of TMD). Nevertheless, given the exploratory nature of OPPERA-2, this conservative tendency in estimating ORs is considered to be a desirable feature of the weighted analysis.

This study is also limited by other problems common to cross-sectional studies of chronic pain conditions. The cross-sectional design means that whether one COPC preceded another could not be verified, and hence the authors refrained from any causal inferences as to the potential contributions of one COPC to another. Recall bias is possible, although this was unable to be assessed. Nonetheless, it seems likely that people with one index pain condition would be more attuned to pain in general and hence more likely to report other pain symptoms. If that occurred, it would artificially inflate the ORs reported here.

\section{Frequency of COPCs and Demographic Patterns of Variation}

Headache affected one-third of subjects, whereas LBP, TMD, and IBS occurred in $15 \%$ to $21 \%$ of subjects, and only $4 \%$ had fibromyalgia. In broad terms, this ranking is consistent with the prevalence reported in community-based samples, ${ }^{1,3,27-29}$ especially after taking into account the truncated 22- to 53-year age range of this OPPERA-2 sample. The age range also explains why age was positively associated with headache, TMD, IBS, and fibromyalgia, all of which have a peak in prevalence in middle-aged adults. In contrast, LBP prevalence increases across successively older age groups in the US population, as was seen here. The surprising result was a lack of gender variation in TMD and IBS, which is in contrast to population studies. ${ }^{3,29}$ Likewise, gender was only weakly associated with the average number of pain conditions and the presence of multiple pain conditions (ie, three or more), which is in contrast to most population-based studies. This aberration is difficult to understand, although it draws attention to biases that are likely in volunteer samples notwithstanding the analytic steps taken to adjust for the sampling design and loss to follow-up.

\section{Overlap of COPCs}

Overlap is a defining feature of COPCs, ${ }^{5}$ and it was not surprising to observe it here. In general, the findings were consistent with other population-based studies reporting substantial overlap of comorbid 
pain conditions with $\operatorname{TMD}^{30}$ headache, ${ }^{31}$ IBS, ${ }^{32}$ $\mathrm{LBP}^{28}$ and fibromyalgia. ${ }^{33}$ Nonetheless, while the overlap of pain conditions is greater than can be explained by chance alone, the current results are consistent with other population-based studies ${ }^{1,3}$ in showing that it is uncommon for individuals to fulfill criteria for multiple pain conditions (eg, three or more COPCs). Conversely, though, the extent of comorbid pain is much greater when the pain is assessed globally, as evidenced here by the majority of COPC cases who reported at least three additional pain locations using a body manikin drawing.

The added knowledge from this study comes from its use of ORs to quantify the degree of overlap among pairs of COPCs. In contrast, previous studies have typically reported overlap in terms of higher-than-expected percentages of overlapping pain conditions among patients with an index pain condition (eg, fibromyalgia). 8,34 Some studies also used percentages to create Euler diagrams, either drawn to scale to indicate the number of people with overlap $^{3}$ or as a qualitative depiction of relationships between COPCs. ${ }^{35}$ One shortcoming of those approaches is their reliance on an external benchmark, usually a population survey, to determine if the observed frequency of pain conditions in a study is greater than expected. For that reason, ORs of association between pairs of COPCs were used as the primary measure of overlap in this paper.

Overall, the degree of overlap seen here was much greater for musculoskeletal pain (ie, overlap of fibromyalgia with TMD and overlap of fibromyalgia with LBP) than for other pairs of COPCs. At first appearance, the large OR between fibromyalgia and TMD might appear tautologic, given that they require examiner assessments of palpation tenderness for classification. Yet the masticatory structures palpated for TMD classification are not among the 18 sites palpated to classify fibromyalgia. Furthermore, in the sensitivity analysis, a similarly strong association was seen when fibromyalgia was classified using the 2011 ACR criteria, a protocol that has no examiner assessment, but which adds the criterion that pain must be disabling. Neither is the strong association observed between LBP and fibromyalgia (as per 1990 ACR) readily explained simply by overlap of classification criteria, given that the "lower back" (as assessed in this study) represents only 2 of the 18 sites assessed for fibromyalgia. Furthermore, the 1990 ACR criteria do not require that pain be disabling (as does this study's classification of LBP). In summary, there is little support for the idea that the observed overlap might simply be tautologic.

A central question regarding these COPCs is whether they represent discrete pain disorders or manifestations of a single syndrome (eg, a functional pain syndrome). ${ }^{5}$ Differences in ORs and in the size of cut-out slices in Fig 1 provide support for both possibilities: fibromyalgia exhibited the largest ORs of association and rarely occurred in isolation, consistent with the idea that a functional pain syndrome is the norm for fibromyalgia cases. Meanwhile, IBS overlapped with fibromyalgia in the univariate analysis, although the relationship was nullified in the multivariable analysis, suggesting that IBS is not readily explained as part of a more widespread functional pain syndrome. Likewise, ORs for headache were smaller, and one-half of headache cases had no other COPCs, suggesting that their headache is equally likely to be discrete or one part of a syndrome. Furthermore, headache was the most frequently reported condition. Given that ORs overestimate the association that would be seen had the prevalence ratios been computed, this reinforces the interpretation that headache is less likely than other COPCs to be syndromic. Overall, the observed patterns of overlap and ORs differ conspicuously according to the index COPC, suggesting that they cannot be viewed as interchangeable components of a single syndrome.

To the extent that any or all of these COPCs represent discrete conditions, the most plausible explanation for observed statistical overlap is that they share common risk factors. ${ }^{7}$ Yet, substantial differences in ORs signify marked variation in degree of overlap, suggesting that risk factors themselves are shared substantially for some pairs of COPCs but not for other pairs. This reinforces the notion that the five COPCs are not interchangeable. Previous OPPERA studies found that TMD is associated with multiple clinical, psychologic, health status, and biologic factors that affect pain perception. ${ }^{36}$ The extent to which those factors are associated with fibromyalgia and the other three COPCs is the topic of other papers in this volume.

Another notable phenomenon was that univariate associations between some pairs of COPCs were nullified after adjusting for other COPCs. This has potential clinical implications when considering how multiple overlapping COPCs contribute to an index COPC. For example, despite a moderately strong univariate association between IBS and fibromyalgia, the multivariable results in Table 4 suggest that fibromyalgia makes no independent contribution to the occurrence of IBS. Conversely, the moderately strong univariate association between TMD and headache was not markedly attenuated after adjusting for the other three COPCs, indicating that each of the overlapping COPCs is making an important contribution to the occurrence of TMD. 


\section{Conclusions}

For all five COPCs studied herein, overlap was the norm: $51 \%$ of people with headache had one or more overlapping COPCs, and the share increased to $90 \%$ for people with fibromyalgia. The degree of overlap between pairs of COPCs varied considerably, being greatest for pairs of musculoskeletal conditions. Furthermore, overlap between some pairs of COPCs could be explained by the presence of other COPCs. Overall, musculoskeletal COPCs showed greater evidence of a syndromic presentation than headache or IBS.

\section{Acknowledgments}

The research reported in this publication was supported by the National Institute Of Dental \& Craniofacial Research (Award Number U01DE017018). Dr Fillingim has equity ownership in Algynomics Inc. The authors have nothing else to disclose.

\section{References}

1. Aggarwal VR, McBeth J, Zakrzewska JM, Lunt M, Macfarlane GJ. The epidemiology of chronic syndromes that are frequently unexplained: Do they have common associated factors? Int J Epidemiol 2006;35:468-476.

2. Diatchenko L, Nackley AG, Slade GD, Fillingim RB, Maixner W. Idiopathic pain disorders-Pathways of vulnerability. Pain 2006;123:226-230.

3. Maixner W, Fillingim RB, Williams DA, Smith SB, Slade GD. Overlapping chronic pain conditions: Implications for diagnosis and classification. J Pain 2016;17(9 suppl):T93-T107.

4. Yunus MB. Editorial review: An update on central sensitivity syndromes and the issues of nosology and psychobiology. Curr Rheumatol Rev 2015;11:70-85.

5. Mayer EA, Bushnell MC. Functional Pain Syndromes: Presentation and Pathophysiology. IASP, 2015.

6. NIH Working Group. Chronic Overlapping Pain Conditions. Summary of NIH Work Group Meeting to Develop Case Definition \& Common Data Elements. National Institutes of Health, 2015. https://www.iprcc.nih.gov/sites/default/files/ Veasley-COPC.pdf. Accessed May 8, 2020.

7. Valderas JM, Starfield B, Sibbald B, Salisbury C, Roland M Defining comorbidity: Implications for understanding health and health services. Ann Fam Med 2009;7:357-363.

8. Aaron LA, Buchwald D. A review of the evidence for overlap among unexplained clinical conditions. Ann Intern Med 2001;134:868-881.

9. Woolf CJ. Central sensitization: Implications for the diagnosis and treatment of pain. Pain 2011;152(3 suppl):s2-s15.

10. Williams DA. Phenotypic features of central sensitization. J Appl Biobehav Res 2018;23(2). pii: e12135.

11. von Elm E, Altman DG, Egger M, et al. The Strengthening the Reporting of Observational Studies in Epidemiology (STROBE) statement: Guidelines for reporting observational studies. J Clin Epidemiol 2008;61:344-349.
12. Fillingim RB, Slade GD, Greenspan JD, et al. Long-term changes in biopsychosocial characteristics related to temporomandibular disorder: Findings from the OPPERA study. Pain 2018;159:2403-2413.

13. Bair E, Brownstein NC, Ohrbach R, et al. Study protocol, sample characteristics, and loss to follow-up: The OPPERA prospective cohort study. J Pain 2013;14(12 suppl):T2-T19.

14. Slade GD, Bair E, By K, et al. Study methods, recruitment, sociodemographic findings, and demographic representativeness in the OPPERA study. J Pain 2011;12(11 suppl):T12-T26.

15. Schiffman E, Ohrbach R, Truelove E, et al. Diagnostic Criteria for Temporomandibular Disorders (DC/TMD) for clinical and research applications: Recommendations of the International RDC/TMD Consortium Network* and Orofacial Pain Special Interest Group. J Oral Facial Pain Headache 2014;28:6-27.

16. Headache Classification Committee of the International Headache Society (IHS). The International Classification of Headache Disorders, 3rd edition. Cephalalgia 2018;38:1-211.

17. Lipton RB, Dodick D, Sadovsky R, et al. A self-administered screener for migraine in primary care: The ID Migraine validation study. Neurology 2003;61:375-382.

18. Longstreth GF, Thompson WG, Chey WD, Houghton LA, Mearin F, Spiller RC. Functional bowel disorders. Gastroenterology 2006;130:1480-1491.

19. Dionne CE, Dunn KM, Croft PR, et al. A consensus approach toward the standardization of back pain definitions for use in prevalence studies. Spine (Phila Pa 1976) 2008;33:95-103.

20. Wolfe F, Smythe HA, Yunus MB, et al. The American College of Rheumatology 1990 Criteria for the Classification of Fibromyalgia. Report of the Multicenter Criteria Committee. Arthritis Rheum 1990;33:160-172.

21. Wolfe F, Clauw DJ, Fitzcharles MA, et al. Fibromyalgia criteria and severity scales for clinical and epidemiological studies: A modification of the ACR Preliminary Diagnostic Criteria for Fibromyalgia. J Rheumatol 2011;38:1113-1122.

22. Isong U, Gansky SA, Plesh O. Temporomandibular joint and muscle disorder-type pain in U.S. adults: The National Health Interview Survey. J Orofac Pain 2008;22:317-322.

23. Janal MN, Raphael KG, Nayak S, Klausner J. Prevalence of myofascial temporomandibular disorder in US community women. J Oral Rehabil 2008;35:801-809.

24. Richardson DB, Rzehak P, Klenk J, Weiland SK. Analyses of case-control data for additional outcomes. Epidemiology 2007;18:441-445.

25. Monsees GM, Tamimi RM, Kraft P. Genome-wide association scans for secondary traits using case-control samples. Genet Epidemiol 2009;33:717-728.

26. Rapoport AM, Bigal ME. ID-migraine. Neurol Sci 2004;25(suppl 3):s258-s260.

27. Jensen R, Stovner LJ. 2008. Epidemiology and comorbidity of headache. Lancet Neurol 2008;7:354-361.

28. Von Korff M, Dworkin SF, Le Resche L, Kruger A. An epidemiologic comparison of pain complaints. Pain 1988;32:173-183.

29. Wilson S, Roberts L, Roalfe A, Bridge P, Singh S. Prevalence of irritable bowel syndrome: A community survey. $\mathrm{Br} J$ Gen Pract 2004;54:495-502.

30. Visscher CM, Ligthart L, Schuller AA, et al. Comorbid disorders and sociodemographic variables in temporomandibular pain in the general Dutch population. J Oral Facial Pain Headache 2015;29:51-59.

31. Scher Al, Stewart WF, Lipton RB. The comorbidity of headache with other pain syndromes. Headache 2006;46(9):1416-1423.

32. Riedl A, Schmidtmann M, Stengel A, et al. Somatic comorbidities of irritable bowel syndrome: A systematic analysis. J Psychosom Res 2008;64:573-582. 
33. Yunus MB. 2012. The prevalence of fibromyalgia in other chronic pain conditions. Pain Res Treat 2012;2012:584573.

34. Aaron LA, Burke MM, Buchwald D. Overlapping conditions among patients with chronic fatigue syndrome, fibromyalgia, and temporomandibular disorder. Arch Intern Med 2000; 160:221-227.
35. Dadabhoy D, Clauw DJ. Therapy insight: Fibromyalgia-A different type of pain needing a different type of treatment. Nat Clin Pract Rheumatol 2006;2:364-372.

36. Slade GD, Ohrbach R, Greenspan JD, et al. Painful temporomandibular disorder: Decade of discovery from OPPERA studies. J Dent Res 2016;95:1084-1092. 


\section{Appendices}

Appendix 1 Associations Between Baseline Phenotype Measures and Cohort Retention

\begin{tabular}{|c|c|c|c|c|c|c|c|}
\hline \multirow[b]{2}{*}{ OPPERA-1 baseline variable } & \multirow[b]{2}{*}{ Scale } & \multicolumn{3}{|c|}{ Unadjusted model ${ }^{\mathrm{a}}$} & \multicolumn{3}{|c|}{ Adjusted model ${ }^{\mathrm{b}}$} \\
\hline & & OR & $P$ & $\operatorname{Sig}^{\mathrm{c}}$ & OR & $P$ & Sig $^{c}$ \\
\hline Study site (4 categories) & N/A & N/A & $6.8 \mathrm{E}-32$ & & & & \\
\hline Age & Per 7.86 units & 1.46 & 3.3E-21 & * & & & \\
\hline Stroop Color-Word log total power at 5 min & Per 0.95 units & 0.80 & 3.3E-07 & * & 0.90 & 3.4E-02 & \\
\hline $\begin{array}{l}\text { Stroop Color-Emotional Word log total power at } \\
5 \text { min }\end{array}$ & Per 0.94 units & 0.80 & 3.7E-07 & * & 0.93 & 1.6E-01 & \\
\hline White race (binary) & N/A & 1.52 & 2.0E-06 & * & & & \\
\hline $\begin{array}{l}\text { Log total power during orthostatic challenge at } \\
5 \mathrm{~min}\end{array}$ & Per 0.86 units & 0.82 & 2.9E-06 & * & 0.92 & 8.8E-02 & \\
\hline $\begin{array}{l}\text { Change in heart rate during orthostatic } \\
\text { challenge }\end{array}$ & $\begin{array}{l}\text { Per } 14.20 \\
\text { units }\end{array}$ & 0.83 & $6.0 \mathrm{E}-05$ & * & 0.90 & 3.7E-02 & \\
\hline Female & N/A & 1.43 & 7.4E-05 & * & & & \\
\hline $\begin{array}{l}\text { STROOP Color-Emotional Word log very low } \\
\text { frequency at } 5 \mathrm{~min}\end{array}$ & Per 0.97 units & 0.84 & $1.1 \mathrm{E}-04$ & * & 0.97 & $5.4 \mathrm{E}-01$ & \\
\hline $\begin{array}{l}\text { Log very low frequency during orthostatic } \\
\text { challenge at } 5 \mathrm{~min}\end{array}$ & Per 0.92 units & 0.85 & 1.3E-04 & * & 0.94 & $1.9 \mathrm{E}-01$ & \\
\hline $\begin{array}{l}\text { Stroop Color-Word log very low frequency at } 5 \\
\text { min }\end{array}$ & Per 0.98 units & 0.85 & $1.5 \mathrm{E}-04$ & * & 0.94 & 2.3E-01 & \\
\hline $\begin{array}{l}\text { Average resting diastolic blood pressure of } 15 \text {, } \\
17,30 \mathrm{~min}\end{array}$ & Per 7.88 units & 1.17 & 1.6E-04 & * & 1.04 & 4.0E-01 & \\
\hline Body mass index $\left(\mathrm{kg} / \mathrm{m}^{2}\right)$ & Per 6.42 units & 1.16 & $2.5 \mathrm{E}-04$ & * & 1.11 & $2.1 \mathrm{E}-02$ & \\
\hline History of 5 respiratory conditions & Per 1.02 units & 1.16 & 3.0E-04 & * & 1.07 & 1.1E-01 & \\
\hline Log total power at 20 min baseline & Per 0.91 units & 0.86 & $3.5 \mathrm{E}-04$ & * & 0.98 & 7.3E-01 & \\
\hline EPQ-R Psychoticism & Per 1.92 units & 0.85 & 4.4E-04 & & 0.93 & 1.1E-01 & \\
\hline POMS Clearheaded-Confused & Per 6.09 units & 1.16 & 6.7E-04 & & 1.11 & $1.8 \mathrm{E}-02$ & \\
\hline EPQ-R Extraversion & Per 3.31 units & 0.87 & 9.3E-04 & & 0.93 & 8.2E-02 & \\
\hline No. of neck sites tender to palpation & Per 3.69 units & 1.13 & 1.6E-03 & & 1.01 & 7.9E-01 & \\
\hline LSL PTSD symptoms & $\begin{array}{l}\text { Per } 11.90 \\
\text { units }\end{array}$ & 0.86 & 1.6E-03 & & 0.80 & $2.1 \mathrm{E}-05$ & * \\
\hline History of osteoarthritis & N/A & 2.35 & 1.9E-03 & & 1.24 & 4.7E-01 & \\
\hline Current smoker & N/A & 0.69 & 2.3E-03 & & 0.62 & 3.0E-04 & * \\
\hline Tension-type headache & N/A & 1.43 & 2.4E-03 & & 1.11 & 4.2E-01 & \\
\hline $\begin{array}{l}\text { No. of palpation tender points: Masticatory } \\
\text { muscles }\end{array}$ & $\begin{array}{l}\text { Per } 11.26 \\
\text { units }\end{array}$ & 1.13 & 3.1E-03 & & 0.98 & 6.4E-01 & \\
\hline PCS Magnification & Per 2.46 units & 0.88 & 3.6E-03 & & 0.88 & 8.8E-03 & \\
\hline SCL-90-R Paranoid Scale & Per 0.55 units & 0.87 & 3.7E-03 & & 0.90 & 3.0E-02 & \\
\hline No. of body sites tender to palpation & Per 3.68 units & 1.13 & 3.8E-03 & & 1.02 & 6.9E-01 & \\
\hline Perceived stress scale score & Per 6.69 units & 0.89 & $6.1 \mathrm{E}-03$ & & 0.89 & 9.7E-03 & \\
\hline PCS Global Score & $\begin{array}{l}\text { Per } 10.38 \\
\text { units }\end{array}$ & 0.88 & $6.5 \mathrm{E}-03$ & & 0.88 & 7.5E-03 & \\
\hline
\end{tabular}

aUnadjusted odds ratios (ORs) of association between baseline variable and odds of OPPERA-2 clinic visit.

${ }^{\mathrm{b}}$ Adjusted ORs are from models adjusting for study site, age, gender, and race.

${ }^{\mathrm{S}} \mathrm{Sig}=P<.0037$ (ie, Bonferroni-adjusted significant association given 135 tests).

SCL-90-R = Symptom Checklist 90-Revised; POMS = Profile of Mood States; VVS = vasovagal syncope; SF-12v2 = Short-Form 12; IVC = In Vivo Coping questionnaire; PILL = Pennebaker Inventory of Limbic Languidness; EPQ-R = Eysenck Personality Questionnaire Revised; CSQ $=$ Coping Strategies Questionnaire; JFLS = Jaw Function Limitation Scale; LSL PTSD = Lifetime Stressor List/PTSD Checklist Civilian Version; PCS = Pain Catastrophizing Scale. 
Appendix 1 (cont'd) Associations Between Baseline Phenotype Measures and Cohort Retention

\begin{tabular}{|c|c|c|c|c|c|c|c|}
\hline \multirow[b]{2}{*}{ OPPERA-1 baseline variable } & \multirow[b]{2}{*}{ Scale } & \multicolumn{3}{|c|}{ Unadjusted model $^{a}$} & \multicolumn{3}{|c|}{ Adjusted model ${ }^{b}$} \\
\hline & & OR & $P$ & Sig $^{c}$ & OR & $P$ & Sig $^{c}$ \\
\hline Log very low frequency at 20 min baseline & Per 0.91 units & 0.89 & 6.7E-03 & & 1.00 & 9.6E-01 & \\
\hline How satisfied with current financial situation & Per 2.74 units & 1.12 & $6.8 \mathrm{E}-03$ & & 1.15 & 3.7E-03 & \\
\hline Satisfied with material standards of life & Per 2.48 units & 1.12 & $1.1 \mathrm{E}-02$ & & 1.12 & 1.8E-02 & \\
\hline History of 7 cardiovascular conditions & Per 0.25 units & 1.10 & $1.1 \mathrm{E}-02$ & & 1.03 & 4.5E-01 & \\
\hline Pressure pain threshold: Temporalis & $\begin{array}{l}\text { Per } 84.93 \\
\text { units }\end{array}$ & 0.89 & 1.3E-02 & & 0.98 & 7.3E-01 & \\
\hline Average resting heart rate $15,17,30 \mathrm{~min}$ & $\begin{array}{l}\text { Per } 10.42 \\
\text { units }\end{array}$ & 1.11 & 1.3E-02 & & 1.07 & $1.2 \mathrm{E}-01$ & \\
\hline $\begin{array}{l}\text { Average resting measures of arterial blood } \\
\text { pressure }\end{array}$ & Per 8.43 units & 1.11 & 1.4E-02 & & 1.05 & 3.4E-01 & \\
\hline LES Total Impact Change score & $\begin{array}{l}\text { Per } 10.39 \\
\text { units }\end{array}$ & 0.89 & $1.5 \mathrm{E}-02$ & & 0.94 & 2.2E-01 & \\
\hline PCS Helplessness & Per 4.68 units & 0.90 & 1.5E-02 & & 0.88 & 8.6E-03 & \\
\hline LSL no. of events in experience list & Per 1.46 units & 0.90 & $1.8 \mathrm{E}-02$ & & 0.85 & $1.2 \mathrm{E}-03$ & \\
\hline LES Sum of Negative Event scores & Per 7.70 units & 0.89 & $1.8 \mathrm{E}-02$ & & 0.89 & 3.1E-02 & \\
\hline $\begin{array}{l}\text { Change in diastolic blood pressure during } \\
\text { orthostatic challenge }\end{array}$ & Per 8.64 units & 0.90 & $2.2 \mathrm{E}-02$ & & 0.99 & 7.6E-01 & \\
\hline Pressure pain threshold: Masseter & $\begin{array}{l}\text { Per } 78.59 \\
\text { units }\end{array}$ & 0.90 & 2.3E-02 & & 1.03 & 5.3E-01 & \\
\hline PCS Rumination & Per 4.21 units & 0.91 & 2.5E-02 & & 0.91 & 5.1E-02 & \\
\hline Mixed headache(s) & N/A & 1.85 & 3.5E-02 & & 1.29 & 4.1E-01 & \\
\hline Migraine headache(s) & N/A & 1.19 & 4.0E-02 & & 1.06 & 5.2E-01 & \\
\hline Pressure pain threshold: TMJ & $\begin{array}{l}\text { Per } 67.93 \\
\text { units }\end{array}$ & 0.91 & 4.6E-02 & & 1.01 & 8.6E-01 & \\
\hline SF12v2 Mental Health Composite Score & $\begin{array}{l}\text { Per } 10.23 \\
\text { units }\end{array}$ & 1.09 & $5.2 \mathrm{E}-02$ & & 1.12 & 1.7E-02 & \\
\hline CSO_Catastrophizing Scale & Per 1.07 units & 0.92 & $5.2 \mathrm{E}-02$ & & 0.92 & 8.7E-02 & \\
\hline SCL-90-R Phobia Scale & Per 0.35 units & 0.91 & 5.3E-02 & & 0.92 & $1.1 \mathrm{E}-01$ & \\
\hline SCL-90-R Psychotic Scale & Per 0.39 units & 0.92 & 6.0E-02 & & 0.95 & 2.6E-01 & \\
\hline Pressure pain threshold: Lateral epicondyle & $\begin{array}{l}\text { Per } 147.30 \\
\quad \text { units }\end{array}$ & 0.92 & $6.0 \mathrm{E}-02$ & & 1.00 & 9.9E-01 & \\
\hline $\begin{array}{l}\text { Thermal temporal summation } 46^{\circ} \mathrm{C} \text { : Slope of } \\
\text { regression }\end{array}$ & $\begin{array}{l}\text { Per } 10.24 \\
\text { units }\end{array}$ & 0.91 & $6.8 \mathrm{E}-02$ & & 0.93 & 2.2E-01 & \\
\hline History of rheumatoid arthritis & N/A & 1.88 & 7.1E-02 & & 1.41 & 3.6E-01 & \\
\hline $\begin{array}{l}\text { CPSQ Q38: No. of different type of headache } \\
\text { in last y }\end{array}$ & Per 1.30 units & 1.08 & 7.3E-02 & & 0.99 & 8.7E-01 & \\
\hline PSQI Global score & Per 3.39 units & 0.93 & 7.9E-02 & & 0.86 & 1.5E-03 & \\
\hline IVC Self-Efficacy & Per 0.99 units & 1.08 & 8.4E-02 & & 1.06 & 2.0E-01 & \\
\hline $\begin{array}{l}\text { Average resting systolic blood pressure at } 15 \text {, } \\
17,30 \mathrm{~min}\end{array}$ & $\begin{array}{l}\text { Per } 10.66 \\
\text { units }\end{array}$ & 1.08 & 8.5E-02 & & 1.07 & 1.4E-01 & \\
\hline CSO Coping Scale & Per 1.41 units & 1.08 & 8.9E-02 & & 1.10 & 3.4E-02 & \\
\hline CSQ Distraction Scale & Per 1.51 units & 1.07 & $9.2 \mathrm{E}-02$ & & 1.12 & 1.7E-02 & \\
\hline SCL-90-R Obsessive-Compulsive Scale & Per 0.61 units & 0.93 & 9.5E-02 & & 0.90 & 2.4E-02 & \\
\hline \multicolumn{8}{|c|}{$\begin{array}{l}\text { aUnadjusted odds ratios (ORs) of association between baseline variable and odds of OPPERA-2 clinic visit. } \\
\text { 'DAdjusted ORs are from models adjusting for study site, age, gender, and race. } \\
\text { cSig }=P<.0037 \text { (ie, Bonferroni-adjusted significant association given } 135 \text { tests). }\end{array}$} \\
\hline \multicolumn{8}{|c|}{$\begin{array}{l}\text { SCL-90-R = Symptom Checklist 90-Revised; POMS = Profile of Mood States; VVS = vasovagal syncope; SF-12v2 = Short-Form 12; IVC = In Vivo Cop- } \\
\text { ing questionnaire; PILL = Pennebaker Inventory of Limbic Languidness; EPQ-R = Eysenck Personality Questionnaire Revised; CSO = Coping Strategies } \\
\text { Questionnaire; JFLS = Jaw Function Limitation Scale; LSL PTSD = Lifetime Stressor List/PTSD Checklist Civilian Version; PCS = Pain Catastrophizing } \\
\text { Scale. }\end{array}$} \\
\hline
\end{tabular}


Appendix 1 (cont'd) Associations Between Baseline Phenotype Measures and Cohort Retention

\begin{tabular}{|c|c|c|c|c|c|c|c|}
\hline \multirow[b]{2}{*}{ OPPERA-1 baseline variable } & \multirow[b]{2}{*}{ Scale } & \multicolumn{3}{|c|}{ Unadjusted model ${ }^{a}$} & \multicolumn{3}{|c|}{ Adjusted model ${ }^{\mathrm{b}}$} \\
\hline & & OR & $P$ & $\operatorname{Sig}^{\mathrm{c}}$ & OR & $P$ & $\mathrm{Sig}^{\mathrm{c}}$ \\
\hline History of 3 endocrine conditions & Per 0.20 units & 1.06 & 9.5E-02 & & 1.00 & 9.7E-01 & \\
\hline History of obstructive sleep apnea & N/A & 0.66 & 1.0E-01 & & 0.54 & 1.9E-02 & \\
\hline $\begin{array}{l}\text { Mechanical pain, aftersensation, } 15 \mathrm{~s}, 256 \mathrm{mN} \\
\text { probe, pain rating }\end{array}$ & Per 8.64 units & 0.92 & $1.1 \mathrm{E}-01$ & & 0.95 & 2.6E-01 & \\
\hline State Anxiety Inventory score & $\begin{array}{l}\text { Per } 10.10 \\
\text { units }\end{array}$ & 0.93 & $1.1 \mathrm{E}-01$ & & 0.93 & 1.3E-01 & \\
\hline $\begin{array}{l}\text { Thermal temporal summation } 48^{\circ} \mathrm{C} \text { : Average } \\
\text { pain } 10 \text { trials }\end{array}$ & $\begin{array}{l}\text { Per } 30.02 \\
\text { units }\end{array}$ & 0.93 & 1.3E-01 & & 0.98 & $6.7 \mathrm{E}-01$ & \\
\hline $\begin{array}{l}\text { Change in blood pressure during orthostatic } \\
\text { challenge }\end{array}$ & Per 9.08 units & 0.94 & 1.3E-01 & & 1.00 & 9.6E-01 & \\
\hline Pain-free jaw opening & $\begin{array}{l}\text { Per } 10.53 \\
\text { units }\end{array}$ & 0.94 & 1.3E-01 & & 1.13 & 1.4E-02 & \\
\hline Trait Anxiety Inventory score & $\begin{array}{l}\text { Per } 10.14 \\
\text { units }\end{array}$ & 0.94 & $1.4 \mathrm{E}-01$ & & 0.92 & $6.9 \mathrm{E}-02$ & \\
\hline POMS Composed-Anxious & Per 6.81 units & 1.07 & $1.4 \mathrm{E}-01$ & & 1.08 & 8.2E-02 & \\
\hline $\begin{array}{l}\text { Mechanical pain, temporal summation, } 256-\mathrm{mN} \\
\text { probe, delta ratings }\end{array}$ & $\begin{array}{l}\text { Per } 12.97 \\
\text { units }\end{array}$ & 0.94 & $1.5 \mathrm{E}-01$ & & 0.95 & $2.8 \mathrm{E}-01$ & \\
\hline $\begin{array}{l}\text { Thermal temporal summation } 46^{\circ} \mathrm{C} \text { : Delta pain } \\
\text { ratings }\end{array}$ & $\begin{array}{l}\text { Per } 26.32 \\
\text { units }\end{array}$ & 0.93 & $1.5 \mathrm{E}-01$ & & 0.93 & 1.4E-01 & \\
\hline Maximum unassisted jaw opening & Per 8.29 units & 0.94 & $1.5 \mathrm{E}-01$ & & 1.16 & 3.3E-03 & \\
\hline Sum of $21 \mathrm{OBC}$ responses & $\begin{array}{l}\text { Per } 11.00 \\
\text { units }\end{array}$ & 1.06 & $1.5 \mathrm{E}-01$ & & 1.04 & 4.3E-01 & \\
\hline $\begin{array}{l}\text { Thermal temporal summation } 50^{\circ} \mathrm{C} \text { : Slope of } \\
\text { regression line }\end{array}$ & $\begin{array}{l}\text { Per } 12.15 \\
\text { units }\end{array}$ & 0.93 & 1.7E-01 & & 0.91 & 1.3E-01 & \\
\hline $\begin{array}{l}\text { Mechanical pain, } 10 \text { stimuli, } 256-\mathrm{mN} \text { probe, } \\
\text { pain rating }\end{array}$ & $\begin{array}{l}\text { Per } 21.69 \\
\text { units }\end{array}$ & 0.94 & $1.8 \mathrm{E}-01$ & & 0.98 & 7.1E-01 & \\
\hline CSQ Ignoring Pain Scale & Per 1.44 units & 1.06 & $1.8 \mathrm{E}-01$ & & 1.08 & 8.9E-02 & \\
\hline SCL-90-R Interpersonal Sensitivity scale & Per 0.54 units & 0.94 & $1.9 \mathrm{E}-01$ & & 0.94 & 1.8E-01 & \\
\hline Overall Positive Affect score & $\begin{array}{l}\text { Per } 16.07 \\
\text { units }\end{array}$ & 1.06 & 2.0E-01 & & 1.05 & 2.4E-01 & \\
\hline SCL-90-R Hostility Scale & Per 0.49 units & 0.95 & $2.2 \mathrm{E}-01$ & & 0.94 & 1.8E-01 & \\
\hline JFLS Opening Limitation & Per 1.69 units & 0.95 & $2.2 \mathrm{E}-01$ & & 0.88 & $8.4 \mathrm{E}-03$ & \\
\hline LES sum of Positive Event scores & Per 5.92 units & 0.95 & 2.3E-01 & & 1.03 & $5.4 \mathrm{E}-01$ & \\
\hline $\begin{array}{l}\text { Thermal temporal summation } 48^{\circ} \mathrm{C} \text { : Slope of } \\
\text { regression line }\end{array}$ & $\begin{array}{l}\text { Per } 11.00 \\
\text { units }\end{array}$ & 0.94 & 2.3E-01 & & 0.92 & 1.5E-01 & \\
\hline $\begin{array}{l}\text { Thermal temporal summation } 50^{\circ} \text { : Average pain } \\
10 \text { trials }\end{array}$ & $\begin{array}{l}\text { Per } 28.54 \\
\text { units }\end{array}$ & 0.95 & 2.4E-01 & & 1.03 & 6.0E-01 & \\
\hline JFLS Verbal and Emotional Expression Limitation & Per 1.17 units & 0.95 & $2.4 \mathrm{E}-01$ & & 0.92 & 9.4E-02 & \\
\hline SCL-90-R Vegetative Scale & Per 0.57 units & 0.95 & 2.6E-01 & & 0.89 & 1.5E-02 & \\
\hline SCL-90-R Anxiety Scale & Per 0.44 units & 0.95 & 2.7E-01 & & 0.91 & 5.1E-02 & \\
\hline JFLS combined global measure & Per 1.25 units & 0.95 & 2.7E-01 & & 0.88 & $9.2 \mathrm{E}-03$ & \\
\hline No. of palpation tender points: TMJs & Per 1.47 units & 1.05 & 2.7E-01 & & 0.96 & 4.0E-01 & \\
\hline JFLS Chewing Limitation & Per 1.51 units & 0.95 & $2.8 \mathrm{E}-01$ & & 0.88 & 9.7E-03 & \\
\hline CSO Praying Scale & Per 2.03 units & 1.05 & 3.0E-01 & & 1.09 & 6.1E-02 & \\
\hline \multicolumn{8}{|c|}{$\begin{array}{l}\text { anadjusted odds ratios (ORs) of association between baseline variable and odds of OPPERA-2 clinic visit. } \\
\text { bAdjusted ORs are from models adjusting for study site, age, gender, and race. } \\
\text { cSig }=P<.0037 \text { (ie, Bonferroni-adjusted significant association given } 135 \text { tests). }\end{array}$} \\
\hline \multicolumn{8}{|c|}{$\begin{array}{l}\text { SCL-90-R = Symptom Checklist 90-Revised; POMS = Profile of Mood States; VVS = vasovagal syncope; SF-12v2 = Short-Form 12; IVC = In Vivo Cop- } \\
\text { ing questionnaire; PILL = Pennebaker Inventory of Limbic Languidness; EPQ-R = Eysenck Personality Questionnaire Revised; CSO = Coping Strategies } \\
\text { Questionnaire; JFLS = Jaw Function Limitation Scale; LSL PTSD = Lifetime Stressor List/PTSD Checklist Civilian Version; PCS = Pain Catastrophizing } \\
\text { Scale. }\end{array}$} \\
\hline
\end{tabular}


Appendix 1 (cont'd) Associations Between Baseline Phenotype Measures and Cohort Retention

\begin{tabular}{|c|c|c|c|c|c|c|}
\hline \multirow[b]{2}{*}{ OPPERA-1 baseline variable } & \multirow[b]{2}{*}{ Scale } & \multicolumn{3}{|c|}{ Unadjusted model ${ }^{a}$} & \multicolumn{2}{|c|}{ Adjusted model ${ }^{b}$} \\
\hline & & OR & $P$ & $\operatorname{Sig}^{\mathrm{C}}$ & OR & $\mathrm{Sig}^{\mathrm{C}}$ \\
\hline $\begin{array}{l}\text { Mechanical pain, aftersenation, } 15 \mathrm{~s}, 512-\mathrm{mN} \\
\text { probe, pain rating }\end{array}$ & $\begin{array}{l}\text { Per } 14.13 \\
\text { units }\end{array}$ & 0.95 & 3.0E-01 & & 1.01 & 9.1E-01 \\
\hline Global Kohn score & $\begin{array}{l}\text { Per } 12.00 \\
\text { units }\end{array}$ & 1.05 & 3.1E-01 & & 0.92 & $1.1 \mathrm{E}-01$ \\
\hline Overall negative affect score & $\begin{array}{l}\text { Per } 17.07 \\
\text { units }\end{array}$ & 0.96 & 3.1E-01 & & 0.93 & $1.2 \mathrm{E}-01$ \\
\hline EPQ-R Lie & Per 3.42 units & 1.04 & 3.3E-01 & & 1.05 & $3.4 \mathrm{E}-01$ \\
\hline History of Sjogren syndrome & N/A & 2.24 & 3.3E-01 & & 2.06 & 4.3E-01 \\
\hline Heat pain tolerance & Per 2.47 units & 0.96 & 3.4E-01 & & 1.00 & $9.6 \mathrm{E}-01$ \\
\hline POMS Energetic-Tired & Per 7.17 units & 1.04 & 3.4E-01 & & 1.09 & 5.6E-02 \\
\hline Probable tension-type headache(s) & N/A & 1.08 & 3.6E-01 & & 0.94 & 5.3E-01 \\
\hline POMS Agreeable-Hostile & Per 5.75 units & 1.04 & 3.6E-01 & & 1.01 & 8.5E-01 \\
\hline SCL-90-R Depression Scale & Per 0.57 units & 0.96 & 3.8E-01 & & 0.92 & 7.7E-02 \\
\hline $\begin{array}{l}\text { Thermal temporal summation } 48^{\circ} \mathrm{C} \text { : Area under } \\
\text { curve pain ratings }\end{array}$ & $\begin{array}{l}\text { Per } 240.60 \\
\quad \text { units }\end{array}$ & 0.95 & 3.9E-01 & & 0.96 & 4.4E-01 \\
\hline History of 3 hematologic conditions & Per 0.30 units & 1.04 & 3.9E-01 & & 0.97 & 4.4E-01 \\
\hline POMS Confident-Unsure & Per 5.96 units & 1.04 & 4.0E-01 & & 1.05 & 2.4E-01 \\
\hline $\begin{array}{l}\text { Mechanical pain, single stimulus, } 256-\mathrm{mN} \text { probe, } \\
\text { pain rating }\end{array}$ & $\begin{array}{l}\text { Per } 13.48 \\
\text { units }\end{array}$ & 0.97 & 4.6E-01 & & 1.03 & $5.9 \mathrm{E}-01$ \\
\hline Mechanical pain threshold: Threshold force & $\begin{array}{l}\text { Per } 166.30 \\
\quad \text { units }\end{array}$ & 0.97 & 4.7E-01 & & 1.01 & 8.1E-01 \\
\hline How do you describe your health overall? & Per 0.61 units & 0.97 & 4.9E-01 & & 0.89 & 1.4E-02 \\
\hline VVS case classification & Per 0.22 units & 0.97 & 4.9E-01 & & 0.92 & 7.9E-02 \\
\hline Count of 20 comorbidities & Per 2.06 units & 1.03 & 5.5E-01 & & 0.88 & 9.3E-03 \\
\hline SF-12v2 Physical Health Composite Score & Per 8.98 units & 0.98 & 5.6E-01 & & 1.06 & 2.0E-01 \\
\hline $\begin{array}{l}\text { Thermal temporal summation } 48^{\circ} \mathrm{C} \text { : Delta pain } \\
\text { ratings }\end{array}$ & $\begin{array}{l}\text { Per } 25.53 \\
\text { units }\end{array}$ & 0.97 & 5.9E-01 & & 0.96 & 4.1E-01 \\
\hline History of 4 neural/sensory conditions & Per 0.76 units & 0.98 & 6.0E-01 & & 0.88 & $4.5 \mathrm{E}-03$ \\
\hline Facial pain interference & $\begin{array}{l}\text { Per } 16.06 \\
\text { units }\end{array}$ & 0.98 & $6.1 \mathrm{E}-01$ & & 0.89 & 1.1E-02 \\
\hline $\begin{array}{l}\text { Thermal temporal summation } 46^{\circ} \mathrm{C} \text { : Area under } \\
\text { curve pain ratings }\end{array}$ & $\begin{array}{l}\text { Per } 235.60 \\
\text { units }\end{array}$ & 0.98 & $6.4 \mathrm{E}-01$ & & 0.98 & 7.3E-01 \\
\hline IVC Passive Coping & Per 0.97 units & 0.98 & 6.6E-01 & & 0.98 & 7.4E-01 \\
\hline $\begin{array}{l}\text { Change in systolic blood pressure during } \\
\text { orthostatic challenge }\end{array}$ & $\begin{array}{l}\text { Per } 13.27 \\
\text { units }\end{array}$ & 1.02 & 6.7E-01 & & 1.02 & $6.0 \mathrm{E}-01$ \\
\hline SCL-90-R Somatization Full Scale & Per 0.46 units & 0.98 & 7.1E-01 & & 0.90 & 2.4E-02 \\
\hline PILL sum score & $\begin{array}{l}\text { Per } 26.96 \\
\text { units }\end{array}$ & 1.02 & 7.1E-01 & & 0.92 & 9.6E-02 \\
\hline Heat pain threshold & Per 3.20 units & 1.02 & 7.2E-01 & & 0.97 & 4.9E-01 \\
\hline $\begin{array}{l}\text { No. of muscle groups with pain on unassisted } \\
\text { opening }\end{array}$ & Per 1.27 units & 1.01 & 7.4E-01 & & 0.95 & 2.9E-01 \\
\hline No. of nonspecific of face/jaw symptoms & Per 2.16 units & 1.01 & 7.7E-01 & & 0.89 & $1.1 \mathrm{E}-02$ \\
\hline \multicolumn{7}{|c|}{$\begin{array}{l}\text { aUnadjusted odds ratios (ORs) of association between baseline variable and odds of OPPERA-2 clinic visit. } \\
\text { bAdjusted ORs are from models adjusting for study site, age, gender, and race. } \\
{ }^{\text {cSig }}=P<.0037 \text { (ie, Bonferroni-adjusted significant association given } 135 \text { tests). }\end{array}$} \\
\hline \multicolumn{7}{|c|}{$\begin{array}{l}\text { SCL-90-R = Symptom Checklist 90-Revised; POMS = Profile of Mood States; VVS = vasovagal syncope; SF-12v2 = Short-Form 12; IVC = In Vivo Cop- } \\
\text { ing questionnaire; PILL = Pennebaker Inventory of Limbic Languidness; EPQ-R = Eysenck Personality Questionnaire Revised; CSO = Coping Strategies } \\
\text { Questionnaire; JFLS = Jaw Function Limitation Scale; LSL PTSD = Lifetime Stressor List/PTSD Checklist Civilian Version; PCS = Pain Catastrophizing } \\
\text { Scale. }\end{array}$} \\
\hline
\end{tabular}


Appendix 1 (cont'd) Associations Between Baseline Phenotype Measures and Cohort Retention

\begin{tabular}{|c|c|c|c|c|c|c|c|}
\hline \multirow[b]{2}{*}{ OPPERA-1 baseline variable } & \multirow[b]{2}{*}{ Scale } & \multicolumn{3}{|c|}{ Unadjusted modela } & \multicolumn{3}{|c|}{ Adjusted model ${ }^{b}$} \\
\hline & & OR & $P$ & $\mathrm{Sig}^{\mathrm{c}}$ & OR & $P$ & Sig $^{\mathrm{C}}$ \\
\hline Rome III IBS classification & N/A & 1.06 & 7.7E-01 & & 0.82 & 3.4E-01 & \\
\hline EPQ-R Neuroticism & Per 3.40 units & 0.99 & 7.8E-01 & & 0.95 & 2.8E-01 & \\
\hline $\begin{array}{l}\text { Thermal temporal summation } 50^{\circ} \mathrm{C} \text { : Delta pain } \\
\text { ratings }\end{array}$ & $\begin{array}{l}\text { Per } 25.16 \\
\text { units }\end{array}$ & 0.99 & 8.0E-01 & & 0.98 & 6.7E-01 & \\
\hline POMS Elated-Depressed & Per 6.34 units & 1.01 & 8.3E-01 & & 1.02 & 7.0E-01 & \\
\hline Facial Characteristic Pain Intensity & $\begin{array}{l}\text { Per } 25.97 \\
\text { units }\end{array}$ & 1.01 & 8.6E-01 & & 0.89 & 9.7E-03 & \\
\hline $\begin{array}{l}\text { Thermal temporal summation } 46^{\circ} \mathrm{C} \text { : Average } \\
\text { pain } 10 \text { trials }\end{array}$ & $\begin{array}{l}\text { Per } 31.10 \\
\text { units }\end{array}$ & 0.99 & 8.7E-01 & & 1.04 & 4.1E-01 & \\
\hline IVC Active Coping & Per 0.87 units & 0.99 & 9.0E-01 & & 1.00 & 9.9E-01 & \\
\hline CSO Distancing Scale & Per 1.41 units & 1.00 & $9.2 \mathrm{E}-01$ & & 1.03 & 4.6E-01 & \\
\hline $\begin{array}{l}\text { Average of left- and right-hand index-ring finger } \\
\text { length }\end{array}$ & Per 0.03 units & 1.00 & $9.2 \mathrm{E}-01$ & & 0.93 & 1.0E-01 & \\
\hline Pressure pain threshold: Trapezius & $\begin{array}{l}\text { Per } 145.70 \\
\quad \text { units }\end{array}$ & 1.00 & 9.4E-01 & & 1.03 & 5.4E-01 & \\
\hline $\begin{array}{l}\text { Mechanical pain, temporal summation, } 512-\mathrm{mN} \\
\text { probe, delta }\end{array}$ & $\begin{array}{l}\text { Per } 16.46 \\
\text { units }\end{array}$ & 1.00 & 9.6E-01 & & 1.02 & $6.1 \mathrm{E}-01$ & \\
\hline $\begin{array}{l}\text { Mechanical pain, } 10 \text { stimuli, 512-mN probe, pain } \\
\text { rating }\end{array}$ & $\begin{array}{l}\text { Per } 27.73 \\
\text { units }\end{array}$ & 1.00 & 9.7E-01 & & 1.07 & 1.7E-01 & \\
\hline $\begin{array}{l}\text { Mechanical pain, single stimulus, } 512-\mathrm{mN} \text { probe, } \\
\text { pain rating }\end{array}$ & $\begin{array}{l}\text { Per } 18.41 \\
\text { units }\end{array}$ & 1.00 & 9.9E-01 & & 1.08 & 1.0E-01 & \\
\hline $\begin{array}{l}\text { Thermal temporal summation } 50^{\circ} \mathrm{C} \text { : Area under } \\
\text { curve pain ratings }\end{array}$ & $\begin{array}{l}\text { Per } 246.20 \\
\quad \text { units }\end{array}$ & 1.00 & $1.0 \mathrm{E}+00$ & & 1.03 & 6.7E-01 & \\
\hline \multicolumn{8}{|c|}{$\begin{array}{l}\text { a Unadjusted odds ratios (ORs) of association between baseline variable and odds of OPPERA-2 clinic visit. } \\
{ }^{\mathrm{b}} \text { Adjusted ORs are from models adjusting for study site, age, gender, and race. } \\
\text { 'Sig }=P<.0037 \text { (ie, Bonferroni-adjusted significant association given } 135 \text { tests). }\end{array}$} \\
\hline \multicolumn{8}{|c|}{$\begin{array}{l}\text { SCL-90-R = Symptom Checklist 90-Revised; POMS = Profile of Mood States; VVS = vasovagal syncope; SF-12v2 = Short-Form 12; IVC = In Vivo Cop- } \\
\text { ing questionnaire; PILL = Pennebaker Inventory of Limbic Languidness; EPQ-R = Eysenck Personality Questionnaire Revised; CSO = Coping Strategies } \\
\text { Questionnaire; JFLS = Jaw Function Limitation Scale; LSL PTSD = Lifetime Stressor List/PTSD Checklist Civilian Version; PCS = Pain Catastrophizing } \\
\text { Scale. }\end{array}$} \\
\hline
\end{tabular}


Appendix 2 Percentage of COPC Cases Endorsing 0, 1, 2, or $\geq 3$ Pain Locations on the Body Manikin

No. of non-index pain locations reported on body manikin* (\% of subjects)

\begin{tabular}{|c|c|c|c|c|c|}
\hline \multirow[b]{2}{*}{ Index COPC } & \multirow[b]{2}{*}{ Weighted no. of cases } & & & & \\
\hline & & 0 & 1 & 2 & $\geq 3$ \\
\hline TMD & 108 & 5.0 & 18.3 & 13.7 & 63.0 \\
\hline Headache & 201 & 30.3 & 10.7 & 10.7 & 48.3 \\
\hline IBS & 134 & 13.8 & 24.9 & 8.0 & 53.3 \\
\hline LBP & 99 & 14.3 & 22.3 & 5.5 & 57.9 \\
\hline
\end{tabular}

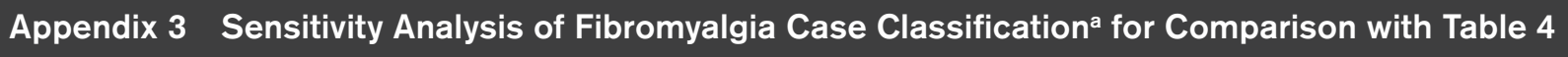

\begin{tabular}{lccccc} 
& TMD & Headache & IBS & LBP & $\begin{array}{c}2011 \text { ACR } \text { Fibro- }^{\text {myalgia }} \\
\text { my }\end{array}$ \\
\hline TMD & & $2.6(1.4,4.7)$ & $2.1(1.1,4.2)$ & $1.9(1.0,3.6)$ & $9.3(2.3,37.5)$ \\
Headache & $3.4(1.9,6.0)$ & & $1.4(0.8,2.5)$ & $1.5(0.8,2.7)$ & $2.8(1.0,8.1)$ \\
IBS & $2.9(1.6,5.3)$ & $1.9(1.1,3.2)$ & & $2.5(1.3,4.6)$ & $1.4(0.5,4.0)$ \\
LBP & $3.6(1.9,6.6)$ & $2.3(1.3,4.0)$ & $3.2(1.7,6.0)$ & & $9.9(4.0,24.9)$ \\
Fibromyalgia & $20.4(6.4,65.3)$ & $6.9(2.8,17.0)$ & $4.2(1.8,9.6)$ & $20.1(8.8,45.7)$ & \\
\hline
\end{tabular}

Data are reported as odds ratios (95\% confidence limits). Unadjusted values are below the diagonal line, and values adjusted for other COPCs are above the diagonal line.

aFibromyalgia was classified using the ACR 2011 criteria. $^{21}$

\section{Appendix 4 OPPERA-2 Hybrid Headache Classification Compared to Strict ICHD-3 Headache Classification}

ICHD-3 classification for TTH and ID-Migraine classification for migraine

\begin{tabular}{|c|c|c|c|c|}
\hline \multirow[b]{2}{*}{$\begin{array}{l}\text { ICHD-3 classification for TTH and } \\
\text { ID-Migraine classification for migraine }\end{array}$} & \multicolumn{4}{|c|}{ No. of subjects classified using ICHD $-3^{*}$ criteria for TTH and migrain } \\
\hline & $\begin{array}{c}\text { No TTH, } \\
\text { no migraine }\end{array}$ & TTH only & Migraine & $\begin{array}{l}\text { TTH and } \\
\text { migraine }\end{array}$ \\
\hline No TTH, no migraine & 194 & 0 & 26 & 0 \\
\hline TTH only & 0 & 71 & 0 & 10 \\
\hline Migraine only & 16 & 0 & 75 & 0 \\
\hline TTH and migraine & 0 & 9 & 0 & 21 \\
\hline
\end{tabular}

International Classification of Headache Disorders 3rd edition (ICHD-3). TTH = tension type headache, classified at the threshold of infrequent headache or more severe headache, but excluding probable TTH.

\section{Appendix 5 Unweighted Analysis of Associations Between Five Pairs of COPCs for Comparison} with Table 4

Odds ratio $(95 \% \mathrm{CL})$ of association between pairs of IPCs: unadjusted (below diagonal) and adjusted for other IPCs (above diagonal)

\begin{tabular}{lccccc} 
& TMD & Headache & IBS & LBP & Fibromyalgia \\
\hline TMD & & $5.0(3.3,7.6)$ & $2.2(1.4,3.4)$ & $1.7(1.1,2.7)$ & $16.0(6.6,39.2)$ \\
Headache & $6.2(4.2,9.0)$ & & $1.4(0.9,2.1)$ & $2.2(1.4,3.4)$ & $1.0(0.5,2.1)$ \\
IBS & $2.8(1.9,4.1)$ & $2.1(1.5,3.0)$ & & $2.1(1.4,3.3)$ & $0.9(0.5,1.8)$ \\
LBP & $3.8(2.6,5.7)$ & $3.3(2.2,4.9)$ & $2.7(1.8,4.1)$ & & $4.7(2.4,9.3)$ \\
Fibromyalgia & $21.9(9.6,49.6)$ & $3.9(2.1,7.3)$ & $2.1(1.2,3.8)$ & $8.1(4.5,14.9)$ & \\
\hline
\end{tabular}

Data are reported as odds ratios ( $95 \%$ confidence limits) associations between pairs of chronic pain conditions. Results in each cell report the odds ratio and $95 \%$ confidence limits $(95 \% \mathrm{CL})$ of associations between pairs of chronic pain conditions. Odds ratios were estimated using binary logistic regression models with no analytic weights to represent the "worst-case" scenario of associations in a convenience sample that ignores the case-control sampling design from when study participants were first enrolled into the OPPERA study.

For the unadjusted odds ratios (below the shaded diagonal), estimates were from univariate logistic regression models predicting odds of the COPC row using the COPC column as the explanatory variable. For the adjusted odds ratios (above shaded diagonal), odds ratios were from logistic regression models predicting odds of the COPC row using all COPC columns as explanatory variables. 
Appendix 6 Sensitivity Analysis of Assumptions Used for Analytic Weights on Estimates of Associations Between Five Pairs of COPCs

\begin{tabular}{|c|c|c|c|c|c|c|}
\hline \multirow{2}{*}{$\begin{array}{l}\text { Assumed TMD } \\
\text { case prevalence } \\
\text { used for com- } \\
\text { puting analytic } \\
\text { weights }\end{array}$} & & \multicolumn{5}{|c|}{ Mean OR (range of cross-validated estimates) } \\
\hline & & TMD & Headache & IBS & LBP & Fibromyalgia \\
\hline \multirow[t]{5}{*}{0.025} & TMD & $\longrightarrow$ & $2.0(1.8,2.2)$ & $2.2(2.0,2.3)$ & $1.9(1.7,2.1)$ & $12.3(9.0,14.8)$ \\
\hline & Headache & $2.6(2.4,2.8)$ & & $1.5(1.4,1.5)$ & $1.5(1.4,1.6)$ & $1.8(1.6,2.1)$ \\
\hline & IBS & $2.8(2.7,3.0)$ & $1.8(1.7,1.9)$ & & $2.7(2.5,3.0)$ & $1.0(0.9,1.4)$ \\
\hline & LBP & $3.3(3.0,3.6)$ & $1.9(1.8,2.0)$ & $3.3(3.1,3.6)$ & & $5.3(4.6,6.3)$ \\
\hline & Fibromyalgia & $17.8(14.1,20.8)$ & $3.4(2.9,4.1)$ & $2.9(2.3,3.5)$ & $9.4(7.9,11.0)$ & \\
\hline \multirow[t]{5}{*}{0.050} & TMD & $\longrightarrow$ & $2.3(2.1,2.6)$ & $2.2(2.0,2.3)$ & $1.9(1.7,2.0)$ & $12.9(9.8,15.4)$ \\
\hline & Headache & $2.9(2.7,3.3)$ & & $1.4(1.4,1.5)$ & $1.5(1.4,1.6)$ & $1.8(1.6,2.1)$ \\
\hline & IBS & $2.9(2.7,3.0)$ & $1.8(1.7,1.9)$ & & $2.7(2.5,2.9)$ & $1.1(0.9,1.4)$ \\
\hline & LBP & $3.4(3.1,3.7)$ & $2.1(2.0,2.2])$ & $3.3(3.1,3.6)$ & & $5.4(4.7,6.4)$ \\
\hline & Fibromyalgia & $19.0(15.5,21.8)$ & $3.8(3.3,4.5)$ & $2.9(2.4,3.5)$ & $9.8(8.5,11.3)$ & \\
\hline \multirow[t]{5}{*}{0.075} & TMD & $\longrightarrow$ & $2.6(2.4,2.9)$ & $2.2(2.0,2.3)$ & $1.8(1.6,2.0)$ & $13.4(10.5,15.8)$ \\
\hline & Headache & $3.3(3.1,3.7)$ & & $1.4(1.3,1.4)$ & $1.6(1.5,1.7)$ & $1.8(1.6,2.0)$ \\
\hline & IBS & $2.9(2.7,3.0)$ & $1.8(1.7,1.9)$ & & $2.6(2.5,2.8)$ & $1.1(0.9,1.4)$ \\
\hline & LBP & $3.4(3.2,3.7)$ & $2.2(2.1,2.3)$ & $3.2(3.1,3.5)$ & & $5.5(4.9,6.5)$ \\
\hline & Fibromyalgia & $20.0(16.6,22.6)$ & $4.1(3.6,4.8)$ & $2.9(2.5,3.5)$ & $10.1(8.9,11.6)$ & 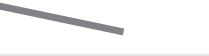 \\
\hline \multirow[t]{5}{*}{0.100} & $\mathrm{TMD}$ & $\longrightarrow$ & $2.9(2.6,3.2)$ & $2.2(2.0,2.3)$ & $1.8(1.6,1.9)$ & $13.8(11.0,16.1)$ \\
\hline & Headache & $3.6(3.4,4.0)$ & & $1.3(1.3,1.4)$ & $1.6(1.5,1.7)$ & $1.8(1.6,2.0)$ \\
\hline & IBS & $2.9(2.7,3.0)$ & $1.8(1.7,1.9)$ & & $2.6(2.4,2.7)$ & $1.1(0.9,1.4)$ \\
\hline & LBP & $3.5(3.2,3.7)$ & $2.3(2.2,2.4)$ & $3.2(3.1,3.5)$ & & $5.6(5.0,6.5)$ \\
\hline & Fibromyalgia & $20.7(17.5,23.2)$ & $4.4(3.9,5.0)$ & $3.0(2.6,3.5)$ & $10.3(9.3,11.7)$ & $=$ \\
\hline \multirow[t]{5}{*}{0.125} & $\mathrm{TMD}$ & $\longrightarrow$ & $3.1(2.8,3.4)$ & $2.2(2.0,2.4)$ & $1.8(1.6,1.9)$ & $14.0(11.5,16.3)$ \\
\hline & Headache & $3.9(3.7,4.3)$ & & $1.3(1.3,1.3)$ & $1.7(1.6,1.8)$ & $1.8(1.6,1.9)$ \\
\hline & IBS & $2.9(2.7,3.0)$ & $1.8(1.7,1.9)$ & & $2.5(2.4,2.7)$ & $1.1(1.0,1.4)$ \\
\hline & LBP & $3.5(3.2,3.7)$ & $2.5(2.3,2.6)$ & $3.2(3.1,3.4)$ & & $5.7(5.1,6.5)$ \\
\hline & Fibromyalgia & $21.3(18.3,23.6)$ & $4.6(4.2,5.2)$ & $3.0(2.6,3.5)$ & $10.5(9.6,11.8)$ & + \\
\hline \multirow[t]{5}{*}{0.150} & TMD & $\sim$ & $3.3(3.1,3.7)$ & $2.2(2.0,2.4)$ & $1.8(1.6,1.9)$ & $14.3(11.9,16.4)$ \\
\hline & Headache & $4.2(3.9,4.6)$ & & $1.3(1.2,1.3)$ & $1.8(1.7,1.9)$ & $1.7(1.5,1.9)$ \\
\hline & IBS & $2.9(2.7,3.1)$ & $1.8(1.7,1.9)$ & & $2.5(2.4,2.6)$ & $1.1(1.0,1.4)$ \\
\hline & LBP & $3.5(3.3,3.7)$ & $2.6(2.4,2.7)$ & $3.1(3.0,3.4)$ & & $5.8(5.2,6.6)$ \\
\hline & Fibromyalgia & $21.8(18.9,23.9)$ & $4.8(4.3,5.4)$ & $3.0(2.6,3.5)$ & $10.7(9.8,11.9)$ & 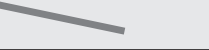 \\
\hline
\end{tabular}

Results in each cell report the mean (range) of the six odds ratios (ORs) of association between pairs of COPCs, each calculated using different analytic weights. Weights were the product of two inverse probabilities, one based on assumed TMD case prevalence (as shown in the first column), and the other based on probability of cohort retention in the OPPERA study, calculated using six prediction models that used random, split-half cross-validation. ORs were then calculated using weighted generalized estimating equation (GEE) models for binary logistic regression with variance correction, as described by Monsees et al.25 For the unadjusted ORs (below the shaded diagonal), estimates were from univariate GEE models predicting odds of the COPC row using the COPC column as the explanatory variable. For the adjusted ORs (above the shaded diagonal), ORs were from multivariable GEE models predicting odds of the COPC row using all other COPC columns as explanatory variables. COPCs were classified as per methods described for primary analysis. 